Article

\title{
Identification of Stress Associated microRNAs in Solanum lycopersicum by High-Throughput Sequencing
}

\author{
María José López-Galiano ${ }^{1}$, Vicente Sentandreu ${ }^{2}$, Amparo C. Martínez-Ramírez ${ }^{2}$, \\ Carolina Rausell ${ }^{1}\left(\mathbb{D}\right.$, M. Dolores Real ${ }^{1}$, Gemma Camañes ${ }^{3} \mathbb{D}$, Omar Ruiz-Rivero ${ }^{1} \mathbb{D}$, \\ Oscar Crespo-Salvador ${ }^{4}$ and Inmaculada García-Robles ${ }^{1, *}$ \\ 1 Department of Genetics, University of Valencia, Burjassot, 46100 Valencia, Spain; maloga2@uv.es (M.J.L.-G.); \\ carolina.rausell@uv.es (C.R.); maria.dolores.real@uv.es (M.D.R.); oruizrivero@gmail.com (O.R.-R.) \\ 2 Servicios Centrales de Soporte a la Investigación Experimental (SCSIE), University of Valencia, Burjassot, \\ 46100 Valencia, Spain; vicente.sentandreu@uv.es (V.S.); amparo.martinez@uv.es (A.C.M.-R.) \\ 3 Plant Physiology Area, Biochemistry and Biotechnology Laboratory, Department CAMN, \\ University Jaume I, 12071 Castellón, Spain; camanes@uji.es \\ 4 Department of Biochemistry and Molecular Biology, University of Valencia, IATA (CSIC), Paterna, \\ 46980 Valencia, Spain; oscar.crespo@uv.es \\ * Correspondence: garciai@uv.es; Tel.: +34-963543178
}

Received: 16 May 2019; Accepted: 17 June 2019; Published: 21 June 2019

\begin{abstract}
Tomato (Solanum lycopersicum) is one of the most important crops around the world and also a model plant to study response to stress. High-throughput sequencing was used to analyse the microRNA (miRNA) profile of tomato plants undergoing five biotic and abiotic stress conditions (drought, heat, P. syringae infection, B. cinerea infection, and herbivore insect attack with Leptinotarsa decemlineata larvae) and one chemical treatment with a plant defence inducer, hexanoic acid. We identified 104 conserved miRNAs belonging to 37 families and we predicted 61 novel tomato miRNAs. Among those 165 miRNAs, 41 were stress-responsive. Reverse transcription quantitative PCR (RT-qPCR) was used to validate high-throughput expression analysis data, confirming the expression profiles of 10 out of 11 randomly selected miRNAs. Most of the differentially expressed miRNAs were stress-specific, except for sly-miR167c-3p upregulated in B. cinerea and P. syringae infection, sly-newmiR26-3p upregulated in drought and Hx treatment samples, and sly-newmiR33-3p, sly-newmiR6-3p and sly-newmiR8-3p differentially expressed both in biotic and abiotic stresses. From mature miRNAs sequences of the 41 stress-responsive miRNAs 279 targets were predicted. An inverse correlation between the expression profiles of 4 selected miRNAs (sly-miR171a, sly-miR172c, sly-newmiR22-3p and sly-miR167c-3p) and their target genes (Kinesin, PPR, GRAS40, ABC transporter, GDP and RLP1) was confirmed by RT-qPCR. Altogether, our analysis of miRNAs in different biotic and abiotic stress conditions highlight the interest to understand the functional role of miRNAs in tomato stress response as well as their putative targets which could help to elucidate plants molecular and physiological adaptation to stress.
\end{abstract}

Keywords: miRNAs; high-throughput sequencing; Solanum lycopersicum; biotic and abiotic stress response; differential expression; miRNA targets; hexanoic acid

\section{Introduction}

In their natural environment, plants are continuously challenged by human actions and abiotic stresses mainly associated with climate change, or biotic hazards as microbial pathogens, insects or herbivores $[1,2]$. Plant growth and development in response to environmental cues implicates intricate 
hormonal regulatory networks [3] and plant gene expression is highly regulated to cope with changes during development and adaptation to different stresses [4].

The availability of plant reference genomes and the advent of high-throughput sequencing technologies have provided new ways to understand the genetic regulation of plant processes from an omic perspective [5], including studies aimed at the comprehensive analysis of small RNAs (sRNAs) by means of profiling endogenous sRNA. sRNAs are currently classified into various groups: MicroRNAs (miRNAs), hairpin derived siRNAs (hp-siRNAs), natural antisense siRNAs (natsiRNAs), secondary siRNAs and heterochromatic siRNAs (hetsiRNAs). The large diversity of sRNA pathways in plants might be an important feature conferring phenotypic plasticity since most sRNA types play relevant roles in defense responses and in epigenetic regulation, although their relative contribution varies among different plant species [6]. In Solanaceae plants, which include more than 3000 species and are among the most economically important plants together with grasses and legumes [5], conserved regulatory cascades triggered by specific miRNAs have been characterized [7], and extensive efforts are devoted to identify miRNAs important for stress tolerance mediated by post-transcriptional stress silencing.

miRNAs are endogenous non-coding small RNA molecules, 20 to $24 \mathrm{nt}$ long [8] generated from primary miRNA transcripts (pri-miRNA) that are mainly transcribed by DNA-dependent RNA-polymerase II $[9,10]$. In plants, pri-miRNAs are generally processed by DICER-LIKE 1 (DCL1) proteins/complexes within the nucleus with the assistance of some cofactors to produce duplexes with a complementary strand of miRNA (miRNA/miRNA*) [10]. Then, most miRNAs are loaded onto ARGONAUTE 1 (AGO1), which lies at the core of RNA-induced silencing complex (RISC) to target coding RNAs by sequence complementarity [11]. As a result, target gene expression is repressed through translational inhibition and/or RNA cleavage [9,12]. In plants, it has been shown that most target transcripts only contain one perfectly complementary site of a single miRNA located anywhere along the target mRNA instead of at the $3^{\prime}$-UTR as in animals [13], and base-pairing leads to degradation of the target mRNA by site-specific cleavage [8]. In contrast, when pairing to the target mRNA is imperfect translational repression occurs [14,15].

Due to their pivotal role in developmental and their trans-regulation functions, miRNAs are ideal candidates to regulate the crosstalk among hormonal signaling pathways [3] as well as gene expression networks, since miRNA main targets are transcription factors that are themselves master controllers of gene expression cascades. Besides the crucial roles of miRNAs in essential processes such as maintenance of genome integrity, signal transduction, hormone homeostasis and innate immunity, they are involved in abiotic and biotic stress responses [16]. Similar to other regulator molecules controlling pathways that cross-talk in multiple plant responses, the comparative analysis of miRNA profiles of plants undergoing different stresses constitutes an ideal strategy to obtain deep insight into the integrated regulation of stress responses.

In this work, we identified and analyzed by high-throughput sequencing miRNAs associated with stress response in tomato (Solanum lycopersicum), a model species for Solanaceae. Thirty-seven miRNA families were detected in tomato plant leaves undergoing six different stress conditions, and twelve miRNAs were found differentially expressed under drought ( 5 miRNAs), heat ( 5 miRNAs), CPB damage (6 miRNAs), P. syringae infection (15 miRNAs), B. cinerea infection (3 miRNAs) and Hx acid treatment (12 miRNAs). In addition, the expression fold-change of 11 stress-responsive miRNAs was validated by RT-qPCR and four of them were selected to assess the expression of their predicted targets.

\section{Materials and Methods}

\subsection{Plant Material and Growth Conditions}

Four-week-old tomato plants of Solanum lycopersicum Mill. cv. Ailsa Craig were grown from germinated seeds in a growth chamber, under the following conditions: 16/8 h light/night cycle, 
$26 / 18{ }^{\circ} \mathrm{C}$ day/night temperature cycle, and $60 \%$ relative humidity (RH). Seeds were irrigated twice a week with distilled water during the first week and with Hoagland solution thereafter [17].

For hexanoic acid $(\mathrm{Hx})$ treatment, pots $\left(748 \mathrm{~cm}^{3}\right)$ containing 1-month-old tomato plants were either watered with $50 \mathrm{~mL}$ of $20 \mathrm{mM} \mathrm{Hx}$ or plain water in the corresponding mocks (non-treated plants). After $48 \mathrm{~h}$, leaf tissue from 3rd and 4 th leaves was harvested, frozen in liquid nitrogen, and stored at $-80^{\circ} \mathrm{C}$.

For Leptinotarsa decemlineata (Colorado potato beetle, CPB) infestation, 15 CPB larvae of different developmental stages were placed on the $3 \mathrm{rd}$ and 4 th leaves of thirty-day-old tomato plants. When necessary, non-cooperative larvae (molting or not eating) were removed and substituted. Leaf tissue left after $3 \mathrm{~h}$ of CPB feeding and that of the non-infested control plants were harvested, frozen in liquid nitrogen, and stored at $-80^{\circ} \mathrm{C}$.

For drought stress experiments, tomato plants where deprived of water during one week and leaf tissue from 3rd and 4 th leaves was collected, frozen in liquid nitrogen, and stored at $-80^{\circ} \mathrm{C}$.

For fungi stress, Botrytis cinerea conidia were collected from 10- to 15-day-old Potato Dextrose Agar PDA plates supplemented with $40 \mathrm{mg} \mathrm{mL}^{-1}$ of tomato leaves and were maintained for $2 \mathrm{~h}$ in the dark with no shaking in Gambor's B5 medium (Duchefa, Haarlem, The Netherlands), supplemented with $10 \mathrm{mM}$ sucrose and $10 \mathrm{mM} \mathrm{KH}_{2} \mathrm{PO}_{4}$. Plants (four-week-old) were challenged by applying $5 \mu \mathrm{L}$ droplets of $1 \times 10^{6}$ spores $\mathrm{mL}^{-1}$, were maintained at $100 \% \mathrm{RH}$, and visible necrosis appeared $48 \mathrm{~h}$ after inoculation. Leaf tissue from $3 \mathrm{rd}$ and 4 th leaves was collected $24 \mathrm{~h}$ post infection (hpi), frozen in liquid nitrogen, and stored at $-80^{\circ} \mathrm{C}$.

For bacterial stress, Pseudomonas syringae pathovar tomato DC3000 was grown at $28^{\circ} \mathrm{C}$ in King's B medium (KB) [18] with Rifampicin $\left(50 \mathrm{mg} \mathrm{mL}^{-1}\right)$. For inoculation, P. syringae bacterial suspensions were adjusted to $5 \times 10^{5}$ colony-forming units (CFU) $\mathrm{mL}^{-1}$ as described previously [19]. Pathogen inoculation was performed by dipping the $3 \mathrm{rd}$ and 4 th leaves into the bacterial suspension. Leaf tissue from 3rd and 4th leaves was collected $48 \mathrm{hpi}$, frozen in liquid nitrogen, and stored at $-80^{\circ} \mathrm{C}$.

For heat stress, tomato plants were grown in the above conditions during 2 weeks and the next two weeks the temperature in growth chamber was increased $5{ }^{\circ} \mathrm{C}\left(31 / 23^{\circ} \mathrm{C}\right.$, light/night cycle). Leaf tissue from 3rd and 4th leaves was collected, frozen in liquid nitrogen, and stored at $-80^{\circ} \mathrm{C}$.

For each stress condition, three biological replicates were generated for each treatment and their corresponding controls. A biological replicate was defined as a pool of leaf tissue from 3rd and 4th leaves from 25 plants.

\subsection{RNA Isolation}

Total RNA was isolated from leaves of tomato plants undergoing 6 different stress conditions (drought, heat, CPB damage, P. syringae infection, B. cinerea infection and Hx treatment), using RiboPure Kit (Ambion. Carlsbad, CA, USA), following the manufacturer's protocol. To remove contaminating genomic DNA from RNA preparations, TURBO DNA-free kit (Ambion, Carlsbad, CA, USA) was used. RNA quality was assessed with the Agilent 2100 Bioanalyzer using the Nano RNA Chip Kit (Agilent, Santa Clara, CA, USA) and RIN value was obtained for each sample. Only samples having a RIN value equal or higher than 7 [20] were used for high-throughput sequencing experiments.

\subsection{Small RNA Libraries Construction and High-Throughput Sequencing}

A total of six groups of RNA samples (drought, heat, CPB damage, $P$. syringae infection, $B$. cinerea infection and Hx treatment) each with three biological replicates, and the corresponding control for each group were prepared. Thirty-six total RNA samples were used to construct sRNA libraries. sRNA fraction was enriched using the Pure Link miRNA Isolation kit (Invitrogen, Carlsbad, CA, USA). The amount and quality of miRNAs in the samples was assessed with the Agilent 2100 Bioanalyzer using the Small RNA Chip Kit (Agilent Santa Clara, CA, USA). sRNA libraries were constructed with the SOLID Total RNA-Seq Kit (Life Technologies ${ }^{\mathrm{TM}}$, Carlsbad, CA, USA). Sequencing adapters were directly ligated to the sRNA, and subsequent reverse transcription to cDNA was carried out. In this 
way, strand orientation is preserved and the strand a miRNA derives from can be exactly mapped. For sequencing both strands simultaneously in a single lane, barcodes were used to generate the libraries. Then, cDNA libraries were prepared and clonal amplification was performed by emulsion PCR using SOLID EZ beads System. Amplified beads were enriched and loaded in 6 lanes on the 5500xl Genetic Analyzer System (Life Technologies ${ }^{\mathrm{TM}}$ ). ECC (Exact Call Chemistry) module (Life Technologies ${ }^{\mathrm{TM}}$ ) was employed for 50 bases length sequencing.

\subsection{Identification of Known and Novel miRNA}

Raw data were preprocessed using XSQ Tools (Life Technologies ${ }^{\mathrm{TM}}$ ) obtaining FASTQ files. Adapter sequences were trimmed with Cutadapt software (version 1.8.3) and sequences were filtered by discarding untrimmed reads and reads of fewer than 15 nucleotides. FASTQC (v.0.11.5) was used to assess data quality (http://www.bioinformatics.babraham.ac.uk). Annotation of sRNA, known miRNAs identification and novel miRNAs prediction was conducted with the sRNAbench tool from sRNAtoolbox webserver (http://bioinfo5.ugr.es/srnatoolbox), applying the hierarchical genome mapping mode, and selecting both the tomato S. lycopersicum reference sequences (SL2_40) and miRBase (release 22.1, http://www.mirbase.org/). In hierarchical mode, all reads that map to a given library are removed from the analysis and can therefore not map again. In this mode, each read can map only to one annotation group.

\section{5. miRNA Validation by Reverse Transcription Quantitative PCR (RT-qPCR)}

RNA samples used for SOLID sequencing were also employed for miRNA validation by RT-qPCR analysis. Total RNA was reverse transcribed to complementary DNA (cDNA) after polyadenylation. For each sample $1000 \mathrm{ng}$ of RNA were polyadenylated in a final volume of $10 \mu \mathrm{L}$ including $1 \mu \mathrm{L}$ of $10 \mathrm{x}$ poly(A) polymerase buffer, $1 \mathrm{mM}$ of ATP and 1 unit of poly(A) polymerase (New England Biolabs, Ipswich, MA, USA ) and incubated at $37^{\circ} \mathrm{C}$ for $15 \mathrm{~min}$ and then at $65^{\circ} \mathrm{C}$ for $20 \mathrm{~min}$. Five hundred ng of polyadenylated RNA were used for 1st strand cDNA synthesis with the Universal primer described in Balcells et al. [21] Reverse transcription reaction was performed using PrimeScript ${ }^{\mathrm{TM}}$ RT reagent Kit (Takara, Kusatsu, Japan) in a final volume of $10 \mu \mathrm{L}$, including $2 \mu \mathrm{L}$ of 5 X PrimeScript ${ }^{\mathrm{TM}}$ Buffer, $0.5 \mu \mathrm{L}$ of PrimeScript ${ }^{\mathrm{TM}}$ RT Enzyme Mix I and $1 \mu \mathrm{M}$ of Universal_RT-primer and it was incubated at $37^{\circ} \mathrm{C}$ for $15 \mathrm{~min}$ followed by enzyme inactivation at $85^{\circ} \mathrm{C}$ for $5 \mathrm{~s}$. The sequence of the RT-primer (Integrated DNA Technologies, Coralville, IA, USA) was 5'-CAGGTCCAGTTTTTTTTTTTTTTTVN-3', where V is $\mathrm{A}, \mathrm{C}$ and $\mathrm{G}$ and $\mathrm{N}$ is $\mathrm{A}, \mathrm{C}, \mathrm{G}$ and $\mathrm{T}$.

RT-qPCR was carried out using $10 \mathrm{ng}$ of cDNA on a StepOnePlus Real-Time PCR system (Life Technologies ${ }^{\mathrm{TM}}$, Carlsbad, CA, USA) thermocycler, following the manufacturer's instructions, using Power SYBR Green PCR Master Mix (Applied Biosystems, Foster City, CA, USA). The cycling parameters were: initial polymerase activation step at $95^{\circ} \mathrm{C}$ for $10 \mathrm{~min}, 40$ cycles of denaturation at $95^{\circ} \mathrm{C}$ for $15 \mathrm{~s}$, annealing and elongation at $60{ }^{\circ} \mathrm{C}$ for $1 \mathrm{~min}$. Specific forward and reverse primers were designed according to Balcells et al. [21]. The list of RT-qPCR primers for stress miRNA amplification can be found in Additional file1, Table S1.

Three biological replicates (with 3 technical replicates each) were analyzed and U6 snRNA gene (GenBank: X51447.1) was used to normalize miRNA expression.

LinRegPCR software [22] was employed for the analysis of RT-qPCR experiments and data were analyzed using Student's $t$-test for statistically significant differences $(p<0.05)$.

\section{6. miRNA Target Prediction and Function Analysis}

Target genes of stress-responsive miRNAs in tomato were predicted using the psRNATarget online tool (http://plantgrn.noble.org/psRNATarget/) and miRNAconsTarget tool from sRNAtoolbox (http://bioinfo5.ugr.es/srnatoolbox). Default parameters for target prediction were used.

Gene ontology enrichment analysis of the identified target transcripts was executed with the online tool AgriGO (GO Analysis Toolkit and Database for Agricultural Community (http://bioinfo. 
cau.edu.cn/agriGO/). Three important components such as biological process, cellular component, and molecular function associated with each GO term were inferred.

\section{7. miRNA Target Validation by RT-qPCR}

RNA samples used for SOLID sequencing were also employed for miRNA target validation by RT-qPCR analysis. Total RNA was reverse transcribed to complementary DNA (cDNA) with RetroScript Kit (Ambion, Carlsbad, CA, USA) following manufacturer instructions with $50 \mathrm{ng} / \mu \mathrm{L}$ oligo (dT)15 (Promega, Madison, WI, USA) and $2.5 \mu \mathrm{M}$ random hexamers (Applied Biosystems) and amplification was carried out on a StepOnePlus Real-Time PCR system (Applied Biosystems) thermocycler, using Power SYBR Green PCR Master Mix (Applied Biosystems, Foster City, CA, USA). The cycling parameters were: initial polymerase activation step at $95{ }^{\circ} \mathrm{C}$ for $10 \mathrm{~min}, 40$ cycles of denaturation at $95^{\circ} \mathrm{C}$ for $15 \mathrm{~s}$, annealing and elongation at $60^{\circ} \mathrm{C}$ for $1 \mathrm{~min}$. For each sample, three biological replicates (with 3 technical replicates each) were analyzed and RPS18 gene (ribosomal protein S18, Gene ID: 107882131) was used to normalize gene expression.

LinRegPCR software [22] was employed for the analysis of RT-qPCR experiments and data were analyzed by Student's $t$-test for statistically significant differences $(p<0.05)$.

The list of RT-qPCR primers for miRNA target genes amplification can be found in Additional file 1, Table S1.

\section{8. miRNA Differential Expression Analysis}

Differential expression analysis of the mature miRNAs was performed with DESeq package implemented in the sRNAde tool from sRNAtoolbox server (http://bioinfo5.ugr.es/srnatoolbox). miRNAs exhibiting padj value $<0.1$ ( $p$-value adjusted for multiple testing using Benjamini-Hochberg method [23]) were further characterized.

The sequence data were deposited in the NCBI Short Read Archive (SRA) with the accession number: SRP113520, BioProject: PRJNA395638 and BioSamples: SAMN07411887 to SAMN07411922.

\section{Results}

\subsection{Overview of Small RNAs Distribution in Tomato Plants under Six Different Stress Conditions}

A total of 36 sRNA libraries from tomato plants comprising 6 stress conditions (drought, heat, $\mathrm{CPB}$ damage, P. syringae or B. cinerea infection, and $\mathrm{Hx}$ treatment) were generated and sequenced using the SOLID technology (Life Technologies ${ }^{\mathrm{TM}}$ ).

Figure 1 shows an overview of the workflow followed to process raw data and predict miRNAs and their targets. First, to obtain high quality data sets, adaptors and low-quantity reads were removed and we obtained 0.23 to 9.5 million clean reads between 15 and $47 \mathrm{nt}$ in length from each of the 36 libraries. For each library, details of raw reads and clean reads are shown in Table 1.

The size distribution of the sRNAs is shown in Figure 2A. Reads of 19 to $24 \mathrm{nt}$ long accounted for over $40 \%$ of the total reads, among which $24 \mathrm{nt}$ long reads were the most abundant in all libraries $(14-21 \%)$.

To sort out the sRNA sequenced reads into categories and identify miRNA sequences in the 36 libraries, reads were mapped to specific databases (miRBase, cDNA, tRNA, and rRNA databases). The sequenced sRNA reads that mapped to the miRBase database were mainly 20-22 nt long for all libraries (Figure 2B). sRNA reads mapped to the miRBase database were more abundant in $P$. syringae libraries (26\%) compared to the rest of libraries that ranged from $8 \%$ to $12 \%$ (Figure 3). A similar frequency distribution of different sRNA species was obtained after mapping to other databases (Figure 3). Reads that mapped to cDNA (sense) database ranged from $13 \%$ to $28 \%$, reads mapped to tRNA database were within $4-10 \%$, and $29 \%$ to $38 \%$ reads mapped to the rRNA database.

Table 1 summarizes the total number of sequences that matched S. lycopersicum genome. 
Table 1. S. lycopersicum sRNA sequencing datasets. Statistics of sRNA sequences for six stress conditions.

\begin{tabular}{|c|c|c|c|c|c|c|c|}
\hline Library & Replicates & Raw Reads & Reads in Analysis & $\begin{array}{l}\text { Unique Reads in } \\
\text { Analysis }\end{array}$ & $\begin{array}{c}\text { Genome Mapped } \\
\text { Reads }\end{array}$ & $\begin{array}{l}\text { Unique Reads Mapped } \\
\text { to Genome }\end{array}$ & $\begin{array}{l}\text { Match Known } \\
\text { miRNAS }\end{array}$ \\
\hline \multirow{6}{*}{$\mathrm{CPB}$} & CPB_control_1 & 2017580 & 1310283 & 202324 & 1007231 & 154699 & 87227 \\
\hline & CPB_control_2 & 2094577 & 1375345 & 213714 & 1073497 & 165203 & 108260 \\
\hline & CPB_control_3 & 1207208 & 781673 & 127111 & 598432 & 96578 & 88872 \\
\hline & CPB_1 & 1287488 & 892095 & 131365 & 678481 & 99049 & 70026 \\
\hline & CPB_2 & 1778426 & 1252398 & 178292 & 969344 & 136223 & 83870 \\
\hline & CPB_3 & 2165134 & 1479772 & 214253 & 1124057 & 163047 & 102550 \\
\hline \multirow{6}{*}{ P. syringae } & Ps_control_1 & 2160524 & 1362621 & 221596 & 1027304 & 166724 & 220908 \\
\hline & Ps_control_2 & 1588889 & 922728 & 164896 & 667568 & 123168 & 171207 \\
\hline & Ps_control_3 & 1787979 & 1051329 & 173251 & 783434 & 129463 & 191246 \\
\hline & Ps_1 & 974244 & 549162 & 93482 & 405265 & 67620 & 253642 \\
\hline & Ps_2 & 1114462 & 590372 & 104438 & 441541 & 74500 & 291917 \\
\hline & Ps_3 & 464118 & 233552 & 42425 & 177202 & 29989 & 217635 \\
\hline \multirow{6}{*}{ B. cinerea } & Bc_control_1 & 1663364 & 1228666 & 148546 & 931181 & 109353 & 71292 \\
\hline & Bc_control_2 & 1764492 & 1224461 & 169339 & 949056 & 125720 & 98452 \\
\hline & Bc_control_3 & 2321326 & 1651189 & 218069 & 1265836 & 163405 & 89453 \\
\hline & Bc_1 & 2452194 & 1789008 & 212957 & 1326215 & 154640 & 132166 \\
\hline & Bc_2 & 11464935 & 9559569 & 760151 & 7069617 & 537263 & 89613 \\
\hline & Bc $\_3$ & 782598 & 556187 & 75621 & 388166 & 53376 & 67491 \\
\hline \multirow{6}{*}{ Drought } & Drought_control_1 & 2686918 & 1922203 & 238355 & 1465597 & 181605 & 62462 \\
\hline & Drought_control_2 & 2980066 & 2139770 & 272662 & 1630658 & 205056 & 98298 \\
\hline & Drought_control_3 & 2865419 & 2197332 & 245822 & 1726340 & 190059 & 52195 \\
\hline & Drought_1 & 2827918 & 2059550 & 259159 & 1571717 & 198434 & 85571 \\
\hline & Drought_2 & 2720161 & 2081553 & 259423 & 1535046 & 198495 & 84087 \\
\hline & Drought_3 & 2950568 & 2118453 & 298178 & 1531771 & 224812 & 117450 \\
\hline \multirow{6}{*}{ Heat } & Heat_control_1 & 1801710 & 1048696 & 191165 & 775561 & 143566 & 145078 \\
\hline & Heat_control_2 & 3224186 & 2180523 & 310215 & 1667525 & 234701 & 107871 \\
\hline & Heat_control_3 & 1969244 & 1183052 & 206622 & 895057 & 156249 & 197825 \\
\hline & Heat_1 & 2719328 & 1900640 & 268834 & 1375793 & 201450 & 104117 \\
\hline & Heat_2 & 2578226 & 1839653 & 304566 & 1412749 & 234794 & 86406 \\
\hline & Heat_3 & 1653823 & 1157590 & 167601 & 915105 & 128069 & 43457 \\
\hline \multirow{6}{*}{ Hexanoic acid } & Hx_control_1 & 3589204 & 2863643 & 316033 & 2223853 & 238842 & 60636 \\
\hline & Hx_control_2 & 2633355 & 2006288 & 227564 & 1569173 & 171024 & 82970 \\
\hline & Hx_control_3 & 1334918 & 918326 & 145154 & 714753 & 109633 & 101580 \\
\hline & Hx_1 & 2284032 & 1643993 & 226204 & 1228535 & 166947 & 144444 \\
\hline & Hx_2 & 3098489 & 2407326 & 276169 & 1852663 & 210496 & 64147 \\
\hline & Hx_3 & 2363533 & 1830552 & 235801 & 1387512 & 177399 & 79684 \\
\hline
\end{tabular}

CPB: Colorado potato beetle; P. syringae: Pseudomonas syringae; B. cinerea: Botrytis cinerea. 


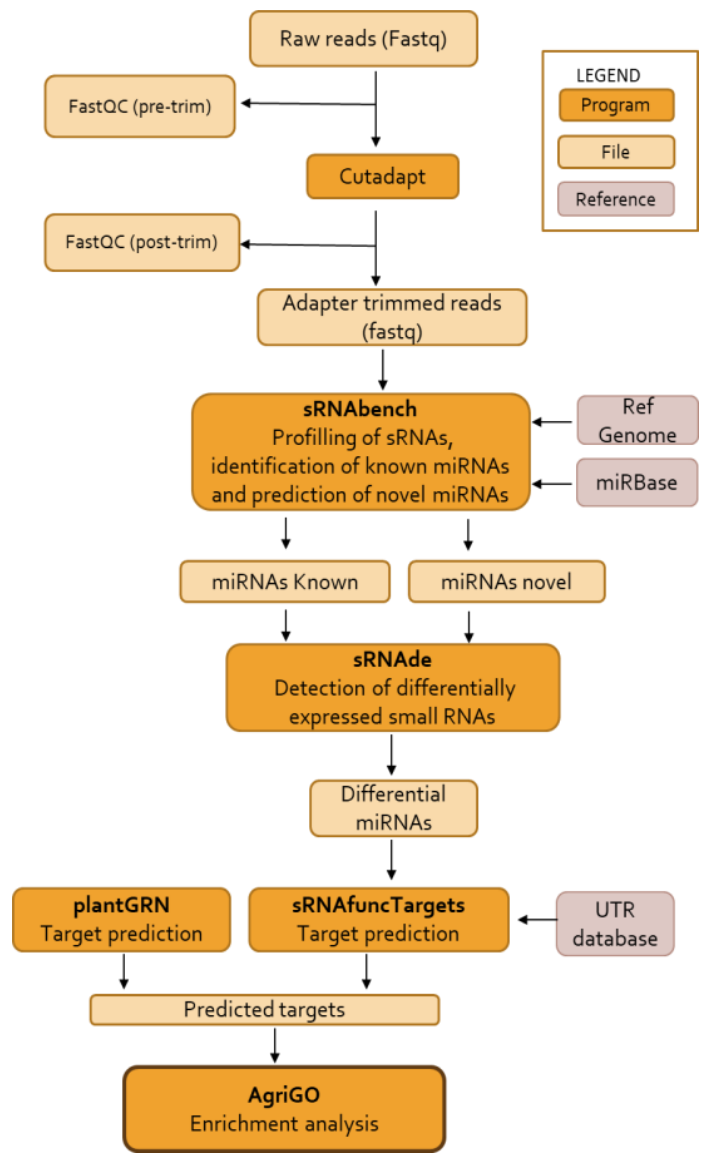

Figure 1. Pipeline workflow of S. lycopersicum miRNA search and target prediction. Pre-trim: pre-trimming, post -trim: post-trimming, Ref genome: reference genome, miRBase: micro RNAs database, miRNAs: micro RNAs, sRNAs: small RNAs, UTR database: untranslated region database.

A

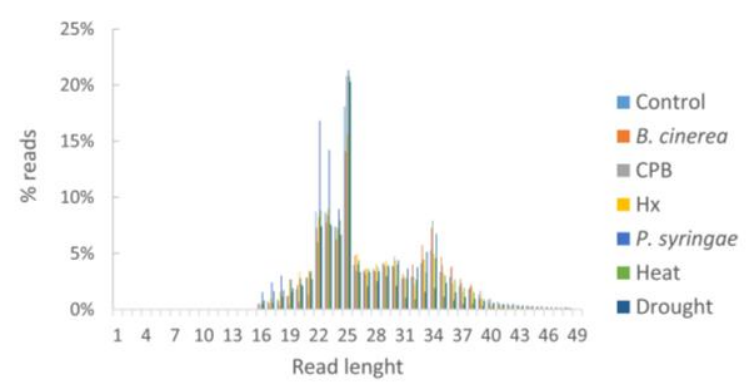

B

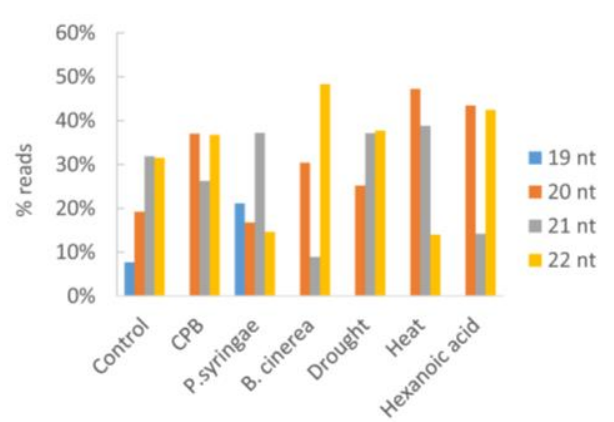

Figure 2. Size distribution of total reads in the thirty-six libraries used in this work. (A) Read length distribution for each stress condition. (B) Distribution of 19 to $22 \mathrm{nt}$ miRNA assigned reads. Control reads correspond to an average of all control plants across treatments.

\subsection{Identification of Known miRNAs}

Conserved miRNAs in tomato were identified by mapping sRNA sequences obtained from each library to the miRNAs database (miRBase 22.1, released in October 2018) selecting S. lycopersicum, S. tuberosum, A. thaliana, and N. tabacum known miRNAs. Homology search was performed and miRNAs with low expression levels (less than 2 reads) were removed. An average of 85 known miRNAs were identified in P. syringae and B. cinerea infected samples, and drought or heat stress samples but only 64 and 28 known miRNAs were detected in CPB infested samples and Hx treated 
samples, respectively (Table 2). A total of 100 known miRNAs belonging to 37 miRNA families were identified in the 36 libraries being sly-miR482e-3p, sly-miR167a, and sly-miR159 those having the largest number of reads in each library (Additional file 2, Table S2).
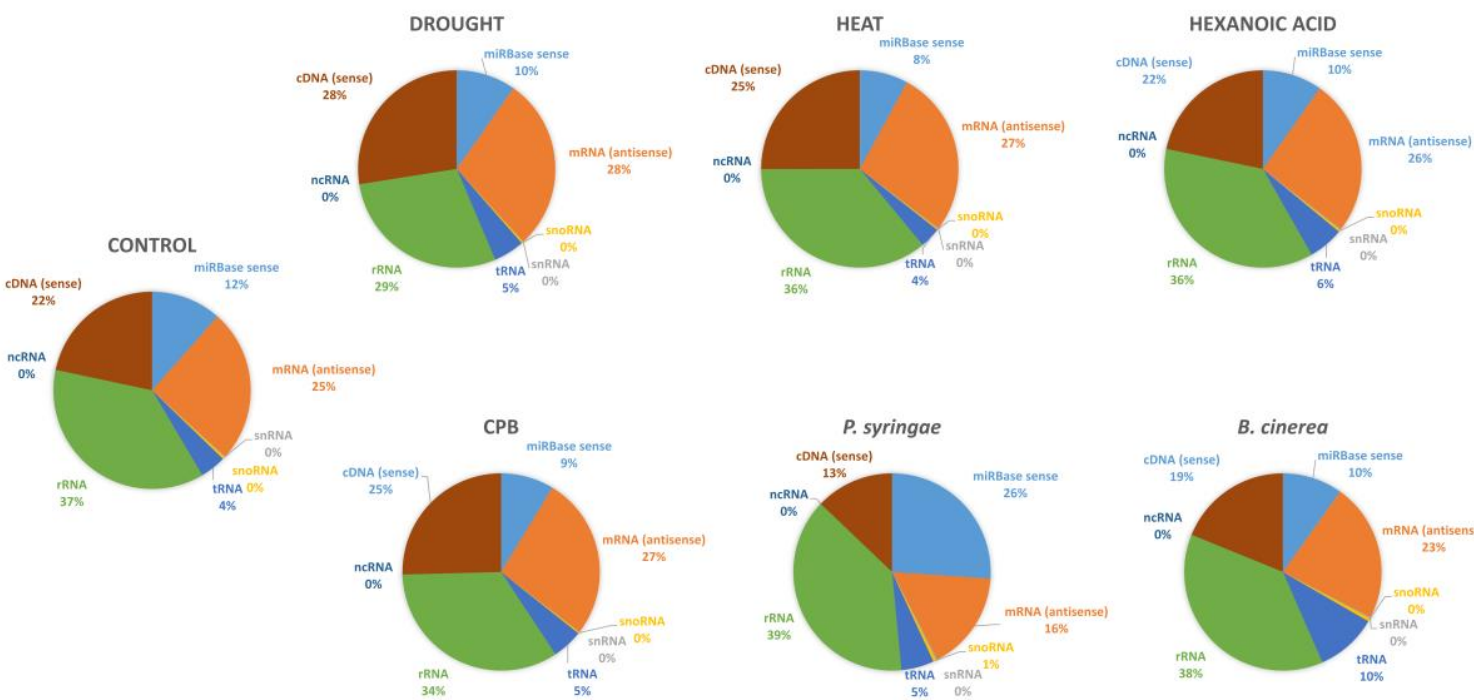

Figure 3. An overview of the frequency of the different small RNAs (sRNA) species present in libraries corresponding to the stress groups. snoRNA, small nucleolar RNA; miRNA, microRNA; tRNA, transfer RNA; rRNA, ribosomal RNA; snRNA, small nuclear RNA; ncRNA, non-coding RNA; complementary DNA cDNA (sense). Control reads correspond to an average of all control plants across treatments.

Table 2. Number of known miRNAs detected in S. lycopersicum plants under six different stress conditions. Only miRNAs present at least in two of the three libraries of each stress condition were considered.

\begin{tabular}{cc}
\hline Library & Known miRNAs \\
\hline Control & 100 \\
CPB & 65 \\
P. syringae & 86 \\
B. cinerea & 84 \\
Drought & 88 \\
Heat & 87 \\
Hexanoic acid & 29 \\
\hline
\end{tabular}

Details of known miRNAs of each library are listed in Additional file 3, Table S3. Among identified miRNAs, sly-miR482 and sly-miR171 families contained the highest number of members (7 and 6, respectively).

\subsection{Identification of Novel miRNAs}

A total of 62 novel miRNAs were identified from the 36 sRNA sequenced libraries using sRNAbench tool from sRNAtoolbox webserver (Table 3). Detailed information of predicted novel miRNAs for each library is presented in Additional file 4, Table S4.

All novel predicted miRNAs were selected with the default parameters of sRNAbench, including the presence of reads from 3p-arm and 5p-arm mature sequences, the duplex formation among those sequences and the presence at the tomato genome of a premiR sequence that could be folded into a hairpin-like structure, similar to those of other miRNAs. Only miRNAs that fulfill those criteria were consider as novel tomato miRNAs. The precursor sequence of these new miRNA candidates varied from 54 to $200 \mathrm{nt}$ in length and the MFE of precursor hairpins ranged from -7.20 to $-152.7 \mathrm{kcal} / \mathrm{mol}$. 
Table 3. Number of novel miRNAs detected in S. lycopersicum plants under six different stress conditions. Only miRNAs present at least in two of the three libraries of each stress condition were considered.

\begin{tabular}{cc}
\hline Library & Novel miRNAs \\
\hline Control & 23 \\
CPB & 13 \\
P. syringae & 30 \\
B. cinerea & 21 \\
Drought & 19 \\
Heat & 25 \\
Hexanoic acid & 28 \\
\hline
\end{tabular}

Sequence and characteristics of eight representative novel miRNAs predicted at RNAfold web server (http://rna.tbi.univie.ac.at//cgi-bin/RNAWebSuite/RNAfold.cgi) are shown in Table 4, and their precursor sequences, as well as the stem-loop hairpin secondary structure are depicted in Figure 4.

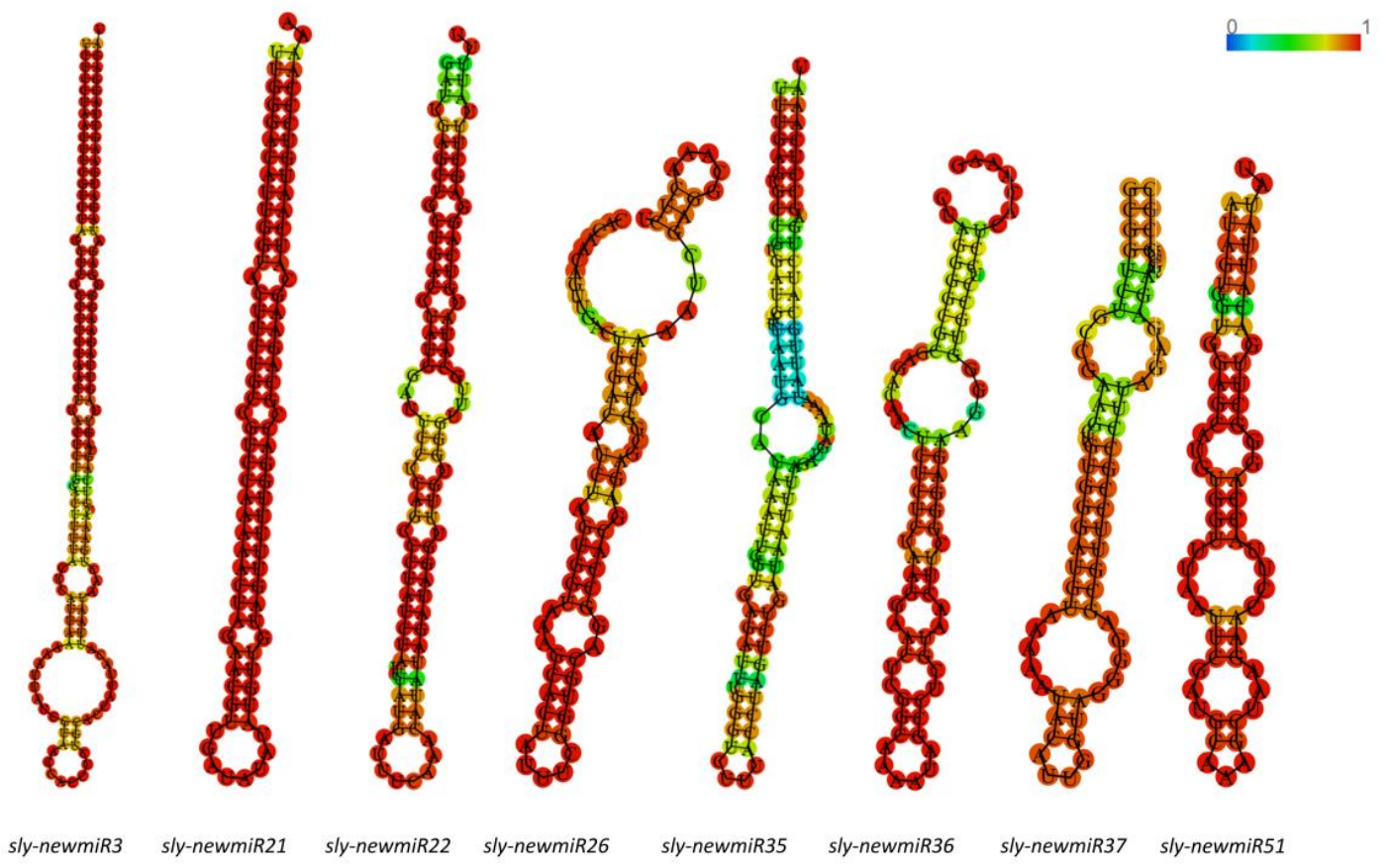

Figure 4. Precursor hairpin structures of eight representative novel S. lycopersicum miRNAs. Mature miRNA sequences are shown. Color gradient indicates base-pair probabilities.

\subsection{Stress-Responsive microRNAs}

To identify stress-responsive miRNAs, normalized expression profiles of known and novel miRNAs in stress samples were compared to their corresponding control samples using DESeq package implemented in the sRNAde tool from sRNAtoolbox. mirRNAs showing a fold change of 2 and a $p$ (adj)-value $<0.1$ were considered differentially expressed (Table 5, Additional file 5: Table S5).

A total of 41 miRNAs were found differentially expressed and predominantly upregulated in stress samples comparing to controls. P. syringae and B. cinerea samples displayed the highest (13) and lowest (3) number of stress-responsive miRNAs, respectively. Thirty-six out of the 41 differentially expressed miRNAs were only identified in one stress condition whereas the remaining 5 responsive miRNAs were not stress specific and were identified in two biotic stresses (sly-miR167c-3p in B. cinerea and P. syringae samples), or two abiotic stresses (sly-newmiR26-3p in drought and Hx treatment samples), or in both biotic and abiotic stresses (sly-newmiR33-3p, sly-newmiR6-3p and sly-newmiR8-3p) (Figure 5). Intriguingly, all miRNAs differentially expressed detected in samples treated with the plant defense inducer Hx were novel miRNAs. 
Table 4. Main features of eight representative novel S. lycopersicum miRNAs.

\begin{tabular}{|c|c|c|c|c|c|c|c|c|}
\hline Name & Sequence & Length & $\%$ GC & Sly Chrom & ChromStart & ChromEnd & Strand & $\begin{array}{c}\text { Minimum Free } \\
\text { Energy (kcal/mol) }\end{array}$ \\
\hline sly-newmiR3-5p & UAACUUCGUCUAGCUCGCCUUC & 22 & 50.0 & 10 & 1709804 & 1709946 & + & -57.1 \\
\hline sly-newmiR21-3p & ACCGCAGAAGCAUCAAUGUCC & 21 & 52.4 & 3 & 10204269 & 10204358 & + & -56.1 \\
\hline sly-newmiR22-3p & GUUUGCAUAUGUCAGGAGCUUU & 22 & 40.9 & 3 & 61786104 & 61786202 & + & -37.0 \\
\hline sly-newmiR26-3p & GCGGUACCAAAUCGAGGCAA & 20 & 55.0 & 4 & 30503172 & 30503253 & - & -21.4 \\
\hline sly-newmir35-5p & GUGCCGUGAUGAUUAAUGCAUAA & 23 & 39.1 & 6 & 37102293 & 37102390 & + & -20.9 \\
\hline sly-newmiR36-3p & GGGAGAAGGGGUGCCUCCUCA & 21 & 66.7 & 7 & 56792405 & 56792486 & + & -26.5 \\
\hline sly-newmiR37-5p & CUGCCGAAGCUGUGGGAUGU & 20 & 60.0 & 8 & 44161949 & 44162021 & + & -19.1 \\
\hline sly-newmiR51-3p & GGUGGAGCAUGUGGUUUAAUUCG & 23 & 50.0 & 2 & 33096229 & 33096295 & - & -15.9 \\
\hline
\end{tabular}

Table 5. Number of miRNAs differentially expressed in S. lycopersicum plants under six different stress conditions.

\begin{tabular}{|c|c|c|c|c|c|c|}
\hline Library & Novel miRNAs & Known miRNAs & Total miRNAs & Upregulated miRNAs & Downregulated miRNAs & Stress Specific miRNAs \\
\hline $\mathrm{CPB}$ & 4 & 2 & 6 & 4 & 2 & 4 \\
\hline P. syringae & 9 & 8 & 17 & 10 & 7 & 14 \\
\hline B. cinerea & 1 & 2 & 3 & 3 & 0 & 2 \\
\hline Drought & 4 & 1 & 5 & 3 & 2 & 3 \\
\hline Heat & 3 & 2 & 5 & 4 & 1 & 4 \\
\hline Hexanoic acid & 12 & 0 & 12 & 7 & 5 & 8 \\
\hline
\end{tabular}




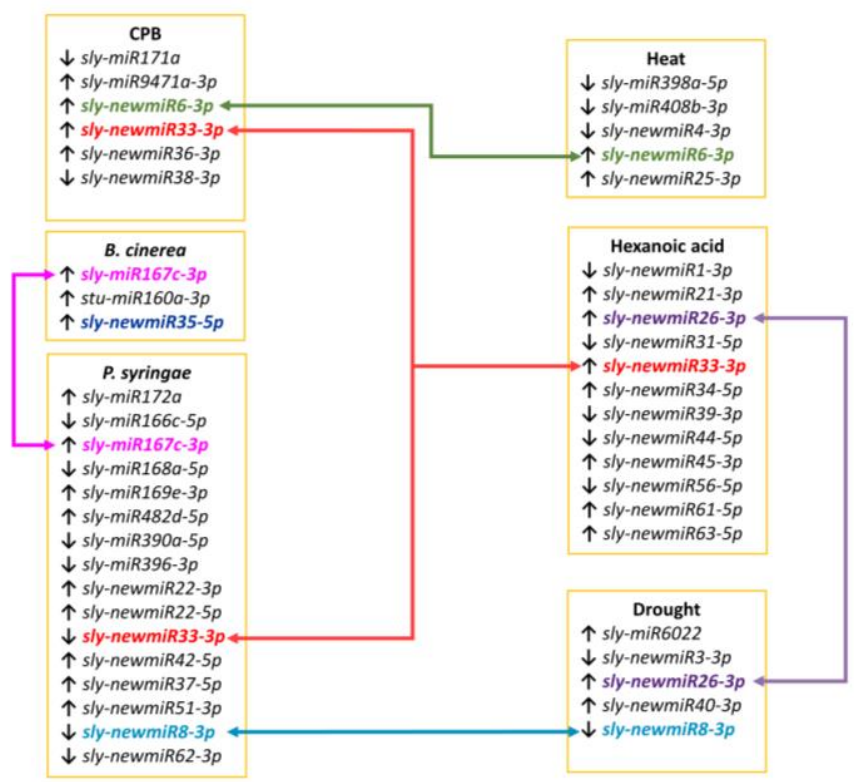

Figure 5. Schematic representation of differentially expressed miRNAs in six stress conditions. Connector lines link miRNAs detected in two or more stress conditions.

\section{5. miRNA Validation}

Eleven out of the 41 miRNAs that were found differentially expressed were selected for validation of the high-throughput sequencing analysis by qRT-PCR, eight known miRNAs (sly-miR408b-3p, sly-miR167c-3p, sly-miR171a, sly-miR6022, sly-miR172c, sly-miR168a-5p, sly-miR482d-5p and sly-miR9471a-3p) and 3 novel miRNAs (sly-newmiR21-3p, sly-newmiR22-3p and sly-newmiR36-3p) (Additional file 6, Table S6). All miRNAs, except sly-miR9471a-3p showed the same tendency in sequencing and RT-qPCR (Figure 6). sly-miR167c-3p was differentially expressed in two different stresses and it was correctly validated in both conditions. Therefore, $91 \%$ of selected miRNAs were validated by RT-qPCR.

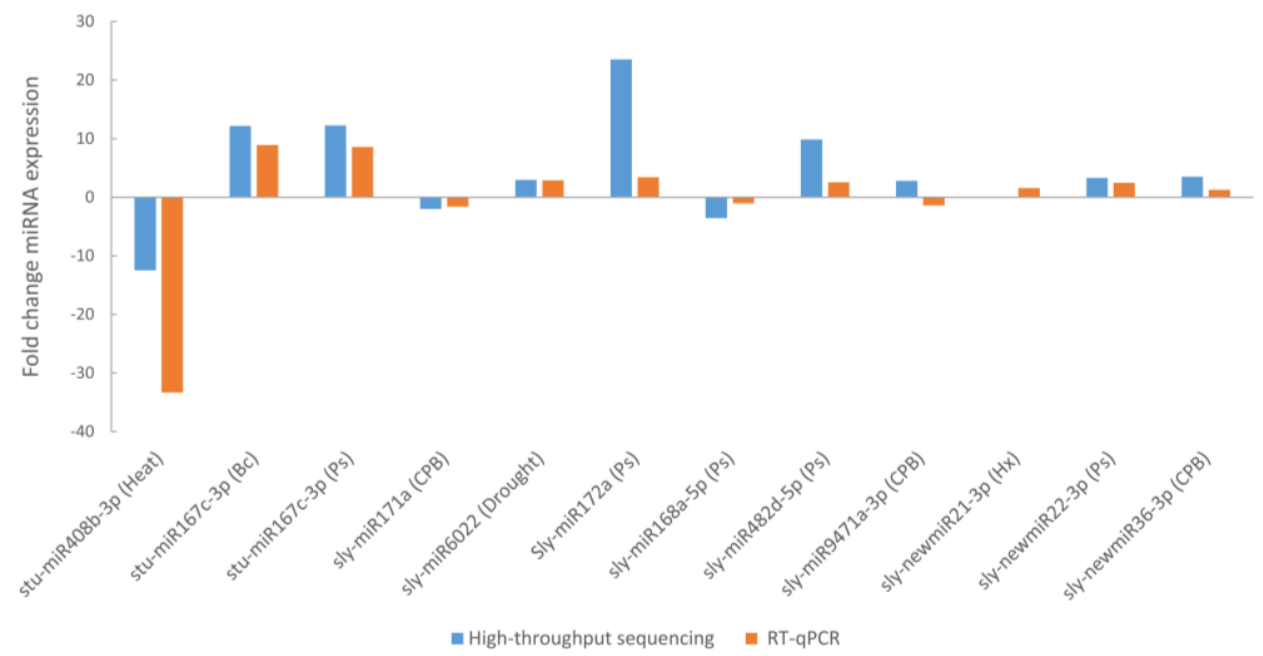

Figure 6. Expression levels of 11 selected stress-responsive miRNAs determined by high-throughput sequencing and RT-qPCR analysis. Selected miRNAs corresponded to 7 known stress-specific miRNA, 1 known miRNA differentially expressed in two stress conditions (sly-miR167c-3p in B. cinerea (Bc) and P. syringae (Ps) infections) and 3 novel stress-specific miRNAs. 


\subsection{Stress-Responsive miRNAs: Targets and Functional Analysis}

The mature sequences of the 41 differentially expressed miRNAs identified were used to search for their targets in tomato genome with the online tools psRNATarget (http://plantgrn.noble.org/ v1_psRNATarget) and miRNAconsTarget from sRNAtoolbox (http://bioinfo5.ugr.es/srnatoolbox), by matching the miRNAs to S. lycopersicum reference genome sequence (SL2_40). A total of 87 target genes for the known miRNAs and 94 targets for the novel miRNAs were predicted (Table 6). Over $82 \%$ of the target genes identified (146) were predicted to be negatively regulated by miRNAs in a miRNA cleavage manner, while the rest (30) might be translationally repressed. Information on the target genes (including target ID and functional annotation) is shown in Additional file 7, Table S7.

Table 6. Number of predicted targets for known and novel differentially expressed miRNA in $S$. lycopersicum plants under six different stress conditions.

\begin{tabular}{ccccc}
\hline Library & $\begin{array}{c}\text { Known miRNAs } \\
\text { Targets }\end{array}$ & $\begin{array}{c}\text { Novel miRNAs } \\
\text { Targets }\end{array}$ & $\begin{array}{c}\text { Total miRNAs } \\
\text { Targets }\end{array}$ & $\begin{array}{c}\text { Stress Specific } \\
\text { Targets }\end{array}$ \\
\hline CPB & 6 & 19 & 25 & 16 \\
P. syringae & 50 & 55 & 105 & 69 \\
B. cinerea & 4 & 3 & 7 & 6 \\
Drought & 18 & 23 & 41 & 25 \\
Heat & 10 & 3 & 13 & 11 \\
Hexanoic acid & 0 & 26 & 26 & 16 \\
\hline
\end{tabular}

The amount of targets predicted varied from one (in the case of sly-miR167c-3p and sly-miR9471a-3p) to 28 (for the novel miRNA sly-newmiR3-5p). A number of the target mRNAs have been described to be involved in metabolism, growth and response to abiotic and biotic stress. In addition, some of the transcripts could be potentially regulated by several miRNAs belonging to different families (Additional file 7, Table S7).

Gene ontology analysis of the miRNAs target transcripts using AgriGO allowed us to identify enriched gene ontology terms significant at 1\% FDR corresponding to binding and catalytic activity in most stress conditions (Figure 7, Additional file 8: Table S8).

\section{7. miRNA Target Validation}

To verify the expression of the miRNAs target genes predicted, primers were designed to perform RT-qPCR of the following tomato genes: Kinesin, PPR, GRAS40, ABC transporter, GDP, RLP1, targeted by sly-miR167c-3p, sly-miR172c, sly-miR171a-3p and sly-newmir22-3p (Table 7).

An inverse expression pattern was observed among the miRNAs and their target genes in all cases (Figure 8). sly-mir167-3p, sly-mir172c and sly-newmir22-3p were upregulated in P. syringae and B. cinerea infected samples and accordingly genes encoding Kinesin-like, PPR, GDP, and RLP1 were downregulated, while sly-mir171a-3p was downregulated and its predicted targets GRAS40 and ABC transporter were upregulated (Figure 8). 
Table 7. Target prediction for four selected miRNAs. Predicted at psRNA target web server (http://plantgrn.noble.org/v1_psRNATarget/) and miRNAconsTarget tool from sRNAtoolbox. Expectation (complementarity between small RNA and their target transcript, lower is best, from 0 to 5 ), UPE (maximum energy to unpair the target site, lower is best), multiplicity (number of putatives sites in the target).

\begin{tabular}{|c|c|c|c|c|c|c|c|c|c|c|c|c|}
\hline miRNA & Target & Expectation & UPE & $\begin{array}{c}\text { miRNA } \\
\text { Start }\end{array}$ & $\begin{array}{c}\text { miRNA } \\
\text { End }\end{array}$ & $\begin{array}{c}\text { Target } \\
\text { Start }\end{array}$ & $\begin{array}{c}\text { Target } \\
\text { End }\end{array}$ & miRNA Aligned_Fragment & Target Aligned Fragment & Inhibition & $\begin{array}{c}\text { Target } \\
\text { Description }\end{array}$ & Multiplicity \\
\hline sly-miR167c-3p & Solyc02g086840.2 & 3.5 & 15.25 & 1 & 20 & 740 & 759 & GGUCAUGCUCGGACAGCCUC & GGGGCUUUCUGAGCAUGAUA & Cleavage & $\begin{array}{c}\text { Kinesin light } \\
\text { chain-like protein }\end{array}$ & 1 \\
\hline sly-miR172a & Solyc01g108180.2.1 & 4.5 & 22.47 & 1 & 20 & 2010 & 2029 & AGAAUCUUGAUGAUGCUGCA & CUCAGGAUCAUCAAGAGUCU & Cleavage & $\begin{array}{l}\text { Pentatricopeptide } \\
\text { repeat-containing } \\
\text { protein (PPR) }\end{array}$ & 1 \\
\hline \multirow[t]{2}{*}{ sly-miR171a } & Solyc08g078800.1.1 & 0.5 & 18.53 & 1 & 21 & 396 & 416 & UGAUUGAGCCGUGCCAAUAUC & GAUAUUGGCGCGGCUCAAUCA & Cleavage & $\begin{array}{c}\text { GRAS family } \\
\text { transcription } \\
\text { factor (GRAS40) }\end{array}$ & 1 \\
\hline & Solyc08g081890.2.1 & 2.5 & 17.79 & 1 & 20 & 3647 & 3666 & UGAUUGAGCCGUGCCAAUAU & AUAUUGGCAUGGCUCUAUCG & Cleavage & $\begin{array}{c}\text { Multidrug } \\
\text { resistance protein } \\
\text { ABC transporter } \\
\text { family }\end{array}$ & 1 \\
\hline \multirow[t]{2}{*}{ sly-newmiR22-3p } & Solyc12g014570.1.1 & 3.0 & 17.57 & 1 & 22 & 1419 & 1440 & GUUUGCAUAUGUCAGGAGCUUU & GGAAUUCUUGACAUAUGCAAAA & Cleavage & $\begin{array}{l}\text { Glycerophosphoryl } \\
\text { diester } \\
\text { phosphodiesterase } \\
\text { family protein } \\
\text { (GDP) }\end{array}$ & 1 \\
\hline & Solyc01g101100.2.1 & 3.0 & 16.50 & 1 & 20 & 1270 & 1288 & GUUUGCAUAUGUCAGGAGCU & GGCUCCUGA-AUAUGCAAAU & Translation & $\begin{array}{l}\text { Receptor-like } \\
\text { protein kinase } \\
\text { (RLP1) }\end{array}$ & 1 \\
\hline
\end{tabular}



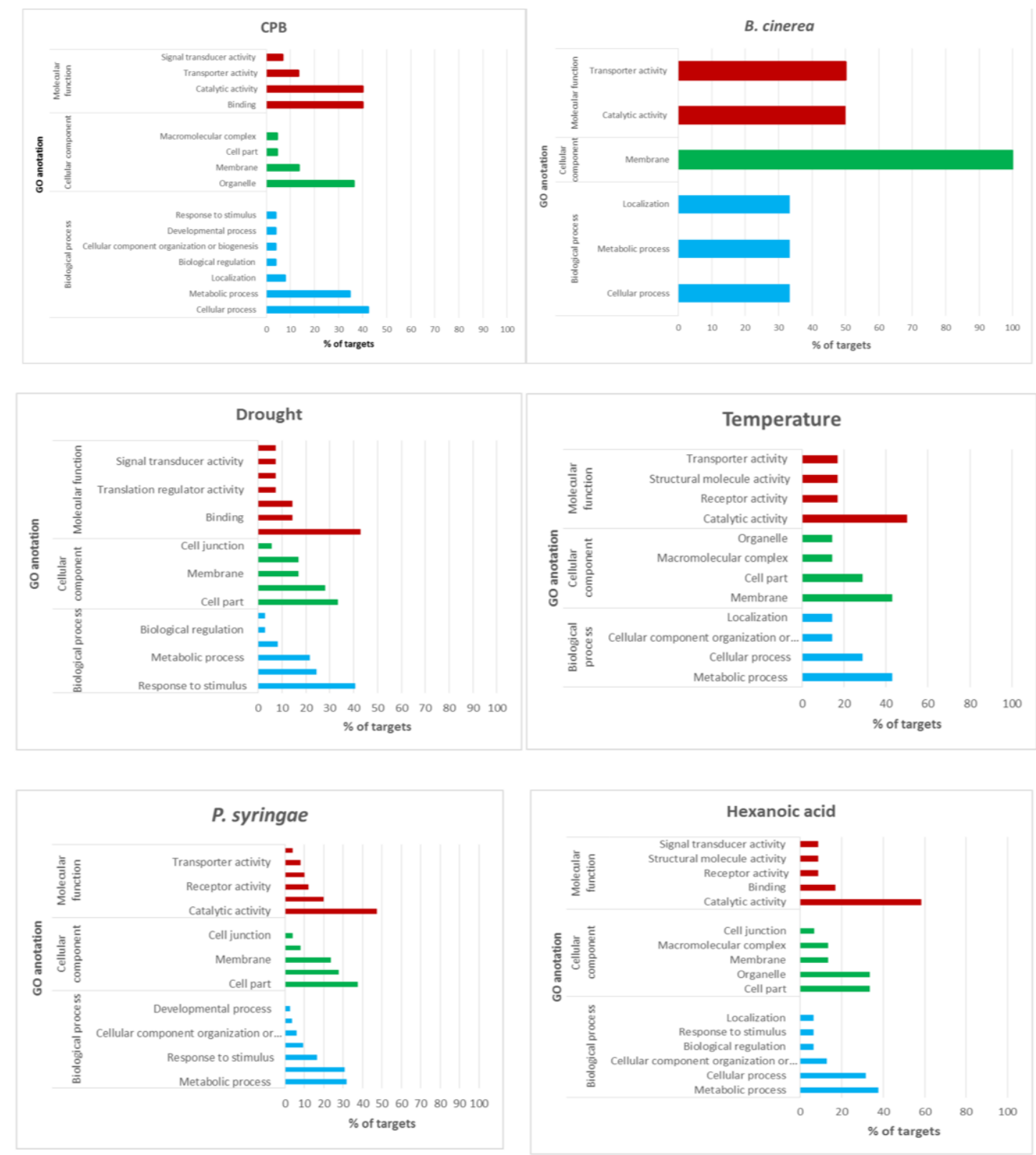

Figure 7. GO analysis of target transcripts regulated by stress-responsive miRNAs. 


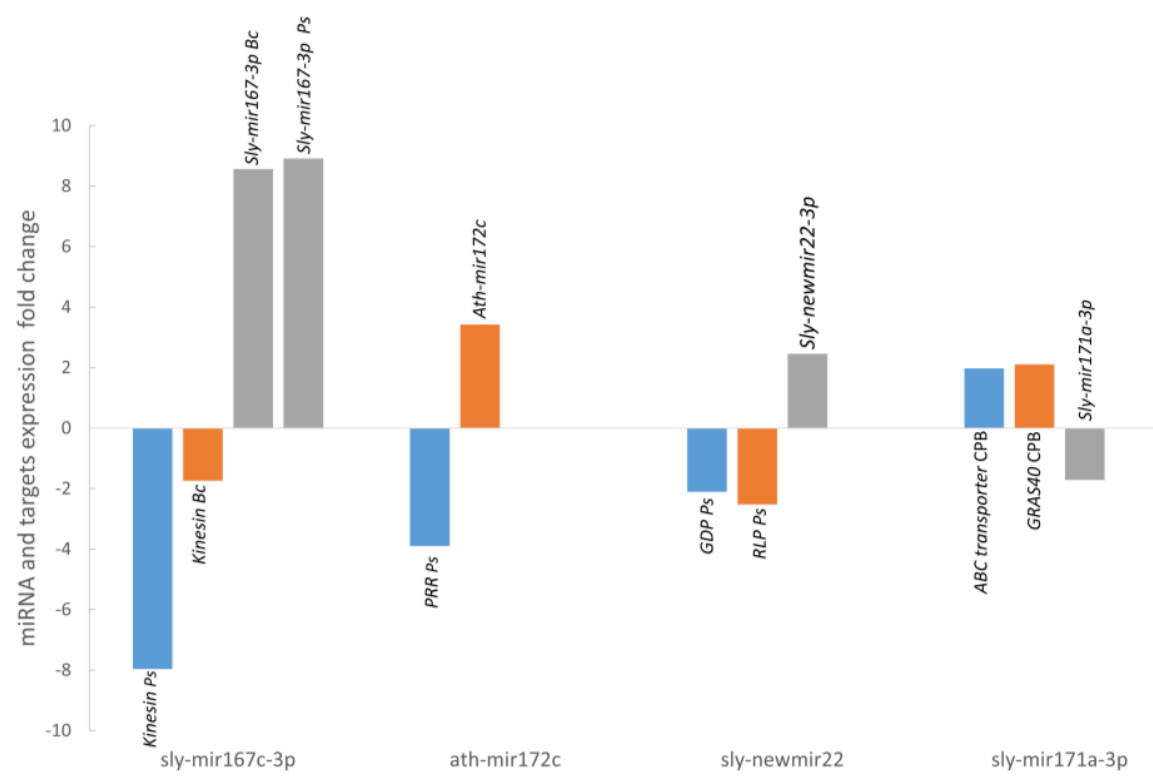

Figure 8. Expression levels of 4 selected miRNAs and their targets determined by RT-qPCR. Selected miRNAs are sly-miR167c-3p and its target, Kinesin-like, RT-qPCR analysis was performed in samples of $B$. cinerea stress and P. syringae stress. ath-miR172c and its target PPR in P. syringae stress. sly-newmiR22-3p and its targets GPD and RPL in P. syringae stress and sly-newmiR171a-3p and its targets, ABC transporter and GRAS40 in CPB stress.

\section{Discussion}

Tomato is one of the most cultivated crops around the world [24] with an annual production of around 164 million tons [25]. Traditionally, tomato has been a research model for fruit development and since the completion of its genome sequence in 2012 [26], it offers an excellent system to study gene regulation in relation to plant stress response. Abiotic stresses, like drought, heat, cold, salinity, and biotic stresses like bacteria or fungi infection or herbivores attack dramatically affect the yield and quality of crops. Recently, the important role of sRNAs as a versatile regulation mechanism of the plant response to stress has been evidenced. In this work high-throughput sequencing of sRNAs with SOLiD technology has been used to obtain the miRNA profile of tomato plants undergoing 5 different stress conditions (drought, heat, $P$. syringae infection, $B$. cinerea infection, and herbivore insect attack with CPB larvae) or chemical treatment with the plant defense inducer Hx. We have detected 104 known miRNAs belonging to 37 families, and 62 novel tomato miRNAs. For the identification of known miRNAs, strict parameters in sRNAbench tool of the sRNAtoolbox were used and no mismatches or gaps allowed. For novel miRNAs predictions, strict default parameters were also used, and only were selected as putative novel miRNAs those having reads for both the $5 \mathrm{p}$-arm and $3 \mathrm{p}$-arm mature miRNAs sequences able to form a duplex, and with a pre-miR sequence mapped in the tomato genome. Read counts differed notably among conserved and novel miRNAs, with the latter displaying lower expression. A few conserved miRNA families such as $m i R 482$, $m i R 167$, and miR159 were the most abundantly expressed (more than $27,000 \mathrm{RPM}$ ), accounting for $36 \%, 20 \%$ and $15 \%$ of all the conserved miRNA reads, respectively. When comparing miRNAs expression patterns among stress samples and controls 40 out of the 165 miRNAs identified were found stress-responsive, which might potentially be implicated in the regulation of stress response in tomato. Supporting the reliability of the miRNA detection by deep sequencing, fold change of eleven random selected differential miRNAs was consistent with the analysis by RT-qPCR ( $91 \%$ miRNAs validated). In all stress conditions, most stress-responsive miRNAs were upregulated ( $55 \%$ in the total 41 stress-responsive miRNAs detected). None of these 41 miRNAs was differentially expressed in all stress conditions, whereas sly-miR167c-3p expression was detected in B. cinerea and P. syringae infection, sly-newmiR26-3p in drought and Hx treatment samples, and sly-newmiR33-3p, sly-newmiR6-3p, 
and sly-newmiR8-3p both in biotic and abiotic stresses. Therefore, it seems that miRNAs expression during stress is dependent on the specific stress to which the plant is subjected.

Tomato stress-responsive miRNAs have been recently identified by high-throughput sequencing in specific stress conditions, such as elevated temperature [27], drought $[28,29]$, and B. cinerea infection [30]. However, there has been no report addressing the global parallel identification of miRNAs in different biotic and abiotic stress conditions to understand the functional role of miRNAs in tomato stress response.

\subsection{Heat Stress-Responsive miRNAs}

In response to heat stress we found two miRNAs highly conserved in plants (sly-miR398a-5p and sly-miR408b-3p) that were both down-regulated, and three novel miRNAs. By tomato deep sequencing, Zhou et al. [27] reported repression of sly-miR408b-3p expression at moderately and acutely elevated temperature ( -1.02 and $-1.70 \log _{2}$ fold change, respectively) whereas sly-miR398a-5p was only significantly down-regulated at acutely elevated temperatures. In Capsicum annuum miR408 and miR398 families were also down-regulated in response to high temperature [31]. In Arabidopsis, miR408 and miR398 and their target genes, including $\mathrm{Cu} / \mathrm{Zn}$ superoxide dismutases (CSD1 and CSD2) and the copper chaperone CCS1 [32,33] have been extensively studied in relation to diverse abiotic stresses (cold, salinity, drought, oxidative and osmotic stress) demonstrating a negative correlation between these miRNAs and CSD1, CSD2 and CCS1 target mRNAs.

\subsection{Drougth Stress-Responsive miRNAs}

In the current study four novel miRNAs and one conserved miRNA (sly-miR6022) were found drought-responsive. Candar-Cakir et al. [28] detected sly-miR6022 among the miR families represented with the top read abundance in two different drought-responsive tomato cultivars (sensitive vs. tolerant), being up-regulated in the drought tolerant genotype in response to water deprivation. When profiling drought-responsive microRNAs in other sensitive and tolerant tomato lines, Liu et al. [29] despite identifying sly-miR6022 did not detect statistically significant differential expression between stress samples and controls. This suggests that different plant species or even cultivars may behave distinctively in plant stress responses regulated by miRNA. It has been proposed that the receptor like protein (RLP) containing leucine-rich repeat (LRR) is targeted by miR6022 not only in tomato plants undergoing abiotic stresses [27] but also in response to plant pathogens [34].

\subsection{B. cinerea Stress-Responsive miRNAs}

It has been reported that plants miRNAs such as miR160, miR167 and miR393 are involved in disease resistance by coordinating plant hormone regulatory networks [35]. These three miRNAs were identified in a tomato deep sequencing analysis upon B. cinerea infection, but only miR160 was found responsive to $B$. cinerea targeting auxin response factors (ARF) [30]. In our study, following $B$. cinerea infection expression of a novel sly-newmiR35-5p was up-regulated as well as that of sly-miR167c-3p and sly-miR160a-3p, corroborating their involvement in the response to B. cinerea infection in tomato leaves.

\subsection{P. syringae Stress-Responsive miRNAs}

Arabidopsis plants challenged with $P$. syringae showed similar expression profile of most of those highly and moderately conserved miRNAs detected in our study [36]. Among others, miR396, miR390 and miR166 families were down-regulated, and miR167, miR169, and miR172 families were upregulated, while miR168 and miR482 were not detected in Arabidopsis [36].

Auxin is considered a pattern-forming phytohormone responsible of plant growth and major developmental processes, many of which are modulated by the auxin response transcription factor (ARF) family [37] targeted by miR167 and miR390. While ARF6 and ARF8 are targets of miR167, expression of $A R F 2, A R F 3$ and ARF4 is regulated by miRNA390 through TAS3-derived ta-siRNAs (trans-acting short-interfering RNAs, a class endogenous secondary siRNAs produced through the 
action of RNA-dependent-RNA-polymerase-6 upon microRNA-mediated cleavage of non-coding TAS RNAs) in Arabidopsis [38-40]. sly-miR167 not only was found up-regulated after bacterial challenging with P. syringae in tomato (present work) and Arabidopsis [41] but also in response to infection with the fungal pathogen Fusarium oxysporum in tomato leaves [42]. In the case of miR390, it does not target a protein-coding mRNA, but rather triggers the production of tasiRNAs from the TAS3 locus, which in turn causes degradation of the ARF3 and ARF4 mRNAs in a miRNA-like fashion [43,44].

miR167 and miR390 have been also described to be responsive to ABA [45,46], a phytohormone that has been involved in the early infection stage of antibacterial defense [47]. After P. syringae infection we have found miR167 and miR390 differentially expressed, as well as miR169, also implicated in ABA functions [48,49].

miRNA families that target genes involved in auxin signaling and ABA response might shape a regulatory network for the molecular adaptation of tomato plants in response to $P$. syringae infection. sly-miR168 expression was up-regulated in tomato plants undergoing P. syringae infection. The miR482/2118 superfamily is unusually diverse (at least 31 isoforms), and variable both in sequence (22 nucleotides rather than 21 nucleotides long) and in expression level. The abundance of miR482 members varies greatly among species and families of plants, having the Solanum genera remarkably high levels of miR482. All variants of this superfamily target the mRNA sequences of genes coding for disease resistance proteins (Resistance-like genes) with nucleotide binding site (NBS) and leucine-rich repeat (LRR) motifs [7] for direct degradation as well as by generating secondary small interfering RNAs (siRNAs) in P. syringae infected Nicotiana benthamiana plants [50], and also in the Arabidopsis 22-nt miR472 related to miR482 [51]. In contrast, sly-miR482d-5p was described to target a PPO encoding gene in potato plants [52] and sly-miR482d-5p targets predicted in the present study were not related to defense functions.

In tomato plants challenged with P. syringae, sly-miR168 expression was found reduced. It has been described that miR168, by regulating ARGONAUTE 1 (AGO1) homeostasis, exerts a regulatory feedback control over other miRNAs biogenesis [53]. Thus, miR168 functioning as an initial regulator modulates the levels of miRNAs coordinating the cross talk of stress response pathways and development programs.

miRNA regulated transcription factors are major nodes coordinating plant growth and differentiation related processes, stress responses, and signaling pathways crosstalk. It is well known that miR396 targets plant GROWTH-REGULATING FACTORS (GRFs) implicated in the regulation of leaf growth, miR172 binds to the $3^{\prime}$-end of APETHALA 2 (AP2) domain transcription factors, which are involved in flowering time control, and miR166 target HOMEODOMAIN LEUCINE ZIPPER (HD-ZIP) transcription factors family genes that regulate plant shoot apical meristems development [54]. Moreover, members of the NF-Y family of transcription factors that play crucial roles in development and in response to adverse environmental conditions are targeted by miR169 [48]. Tomato plants challenged with P. syringae showed altered profiles of all those miRNAs indicating that physiological adaptation to pathogen attack requires an integrated expression of genes responsible of immune defense and growth.

\subsection{CPB Stress-Responsive miRNAs}

Very few studies addressed miRNA identification by high-throughput sequencing in plants attacked by insects. We have detected two conserved miRNAs (sly-miR171a and sly-miR9471a-3p) and four novel miRNAs differentially expressed in CPB infested tomato plants. miR171 family was significantly increased in wounded Nicotiana attenuata leaves treated with Manduca sexta oral secretions whereas miR171 potential targets GRAS proteins were down-regulated [55]. Among other miRNAs, miR171 was considered as a JA-independent miRNA [55]. In contrast, Gao et al. [56] profiling miRNAs under wound treatment in Aquilaria sinensis found consistently lower expression levels of miR171 family members in wounded stems compared to healthy stems. Similarly, in our study, sly-miR171a was repressed in tomato plants damaged by CPB. Regarding sly-miR9471a-3p, this miRNA was among 
the most abundant miRNAs families detected in Alternaria alternata infected tomato plants, although no differential expression was observed comparing to control plants [57].

\section{6. miRNAs Expressed in Response to the Priming Agent $\mathrm{Hx}$}

As a result of exposure to stress, plants often become more resistant to future exposure through a memory acquisition process named priming, which can also be mediated by natural compounds like Hx [58]. Plant defense priming allows plants to respond to biotic and abiotic stress better than unprimed plants avoiding the fitness costs associated with permanent full defense activation [59]. No differentially expressed conserved miRNAs following Hx treatment were identified and twelve novel Hx responsive miRNAs were found.

Little is known about the molecular mechanisms underlying priming process, but sustained impaired levels of signaling molecules after the initial stress that boost extensive transcriptional reprogramming of defense genes upon further challenge, as well as histone acetylation and DNA methylation epigenetic modifications have been proposed as critical regulators of defense priming [60-62]. A role for miRNAs in stress memory has been recently described based on their specific functions as translational inhibitors. Induction of isoforms of the microRNA miR156 has been reported following heat stress, and repression of their target genes was needed for the maintained enhanced expression of memory genes and for physiological heat stress memory [63]. In addition, Soto-Suárez et al. [64] provided evidence that miRNAs might be sustaining defense priming by demonstrating that reduced miR396 levels and up-regulation of its target genes sensitized plants to mount more robust defense responses during pathogen infection even when in the absence of pathogen challenge, the transcriptome and development of modified plants with diminished miR396 activity could not be distinguished from those in wild-type plants.

\section{7. miRNAs Diferentially Expressed across Stresses}

To the best of our knowledge, there is no research work on global expression profiling of tomato miRNAs in response to $P$. syringae infection. We have detected eight conserved differentially expressed miRNAs one of them also responsive to $B$. cinerea infection (sly-miR167c-3p), and seven novel miRNAs two of which were responsive to other stresses as well (sly-newmiR8-3p also down-regulated in response to drought, and sly-newmiR33-3p responsive to CPB infestation or Hx treatment) (Figure 5). Among the eight known P. syringae-responsive miRNAs identified, five miRNAs (ath-miR172c, sly-miR166c-5p, sly-miR168a-5p, sly-miR396-3p and sly-miR390a-5p) belong to families highly conserved in plants, two are moderately conserved (sly-miR167c-3p and sly-miR169e-3p), and sly-miR482d-5p is a non-conserved plant miRNA. Highly and moderately conserved miRNA families have high expression levels and play relevant functions in plant development regulating gene expression of multiple targets in numerous plant species [13]. Our analysis revealed several miRNA families that target genes involved in a number of essential pathways mainly regulating auxin signaling (miR167 and miR390), development and reprograming processes (miR396, miR172, miR169 and miR166), and stress defense (miR167, miR169 and miR390), especially ABA response.

In our work, we analyzed the miRNA profile of tomato plants treated with the natural defense priming inducer $\mathrm{Hx}$ that protects tomato against B. cinerea and P. syringae with high efficiency [65]. Interestingly, although no differentially expressed conserved miRNAs following Hx treatment were detected, two of the twelve novel Hx responsive miRNAs found (sly-newmiR33-3p and sly-newmiR26-3p) showed varied expression in tomato plants subjected to other stresses (CPB infestation and P. syringae infection, or drought, respectively, Figure 5). These results suggest that Hx treatment might exert its priming effect by triggering persistent expression of a complex network of miRNAs (not all of them necessarily involved in known stress signaling cascades) that upon exposure to a subsequent stress regulate an enhanced, more efficient or more rapid response. Further research will be needed to uncover the role of each Hx responsive novel miRNAs and their target genes, and decipher how they contribute to Hx defense priming. 


\subsection{Validation of Stress-Responsive miRNAs and Their Targets}

A total of 181 targets genes were predicted ( 87 for conserved miRNAs and 94 for novel miRNAs) using the mature sequences of the 41 differentially expressed miRNAs. Most of the targets (82\%) were predicted to be negatively regulated in a miRNA cleavage manner, therefore an opposite expression profile is expected for those miRNA-target pairs. We have selected 5 of these targets for validation with RT-qPCR focusing on P. syringae infection and CPB larvae infestation, two stress conditions for which there is a lack of information about their miRNA expression profile. We have selected targets for miRNAs that were validated with deep sequencing and RT-qPCR and that were either stress specific conserved miRNAs, sly-miR171a for CPB (GRAS and ABC transporter) and sly-miR172c for (PPR protein), stress specific novel miRNA as sly-newmiR22-3p for P. syringae infection (GDPDL3 and RLP1) or multi-stress miRNA, as sly-miR167c-3p for P. syringae and B. cinerea infection (Kinesin).

sly-miR172c expression was upregulated in tomato plants after infection with P. syringae (3.89-fold). A pentatricopeptide repeat-containing protein (PPR) that belongs to the Tandem Repeats protein group is one of targets predicted for this miRNA. In Arabidopsis, PPR proteins is one of the largest protein families with at least 466 genes in its genome [66,67]. Many repeat protein in plants, as PPR, LRR or WD40 have a role in primary metabolism but also act as regulators in plant secondary metabolism including abiotic and biotic stress response [68,69]. In Solanum tuberosum, PPR expression was downregulated upon Ralstonia solanacearum infection [70] and in Arabidopsis, the absence of this protein led to an increase in the sensibility to a necrotrophic fungal pathogen and hypersensitivity to abiotic stresses such as salinity, glucose, and ABA [71]. In this work, PPR expression was downregulated in tomato leaves after P. syringae infection (3.42-fold).

sly-miR67c-3p expression was upregulated upon P. syringae and B. cinerea infection (8.91-fold, 8.57-fold, respectively) and there is only one target predicted for this miRNA, a Kinesin light chain-like protein. Kinesin is a motor protein that moves along the microtubules of the cytoskeleton. The actin cytoskeleton in plants has been proposed to be associated to plant cell shape, plant development, and stress response [72]. Both biotic and abiotic stresses might be affected by the continuous activity and reorganization of the host actin cytoskeleton [72,73]. In Arabidopsis, Shimono et al. [74] showed that kinesin mutant plants had less symptoms after $P$. syringae infection and they speculate with the possibility of and integrative function for kinesin, supporting cellular traffic during pathogen invasion, and immune signaling. In this work, we have found a reduction of the kinesin gene expression after P. syringae infection (-7.96-fold) and B. cinerea infection (-1.74-fold).

The expression of sly-miR171a miRNA was reduced in tomato plants (1.71-fold) after CPB larvae attack. Among the five predicted targets for this miRNA, three of them are members of the GRAS family of transcription factors (subfamily HAM): GRAS8, GRAS24 and GRAS40. In tomato, Huang et al. [75] by $5^{\prime}$-RACE analysis demonstrated the regulation of GRAS24 and GRAS40 by sly-miR171 and in Arabidopsis, it had been previously reported that their closest homologous (AtSCL6, 22, 27) were post-transcriptionally regulated by ath-miR171 [76,77]. Huang et al., [78] established the implication of GRAS24 in the regulation of gibberellin and auxin homeostasis. Maryose et al. [79] showed that transcript levels of eight tomato GRAS genes increased in response to mechanical stress. Also, a GRAS homologue in Nicotiana attenuate and Solanum nigra has been found to be induced upon M. sexta attack [80]. In this work we have analyzed by RT-qPCR the expression of the three GRAS genes predicted as targets of sly-miR171a. GRAS8 and GRAS24 gene expression was not affected after CPB larvae attack (data not shown) but GRAS40 expression was increased by a 2-fold, which could account for its participation in tomato response to herbivore attack.

The other putative target of sly-miR171a is a multidrug resistance protein of the ABC transporter family, which use the energy released by ATP hydrolysis to drive the exchange of compounds across biological membranes even against electrochemical gradients [81]. Oral secretions of herbivore chewing insects contains compounds that can be recognized by plants triggering a defense response $[82,83]$ in which plants accumulate secondary metabolites and inhibitory proteins to stop pathogen invasion and insect attack. There are evidences indicating that $\mathrm{ABC}$ transporters mediate the secretion of 
plant defense compounds into both the rhizosphere and the apoplast, or onto the plant surface [84]. In Nicotiana tabacum, Bienert et al. [85] showed that the ABCG5/PDR5 transporter expression in leaves was very low but it was induced after wounding by the herbivore $M$. sexta. In this work, the tomato ABC transporter augmented its expression (1.98-fold) in leaves following CPB larvae attack, which would be in agreement with an implication of the pair sly-miR171a-ABC transporter in tomato response to herbivore attack.

sly-newmiR22-3p expression was found increased after P. syringae infection (2.46-fold). Two of its predicted targets were a Receptor-like protein kinase (RLP1), which has a LRR motif, and a Glycerophosphoryl diester phosphodiesterase family protein (GDPDL3). The plant receptor-like protein kinases with leucine-rich repeat motif (LRR-RLK) is one of largest plant protein families and they are implicated in hormone and stress response pathways and in plant developmental processes [69]. Some members of LRR-RLK family and GDPL proteins participate in the formation of plant cell wall that acts as a barrier for both biotic and abiotic stresses [86,87]. In this work, we have detected about 2-fold reduction of RLP1 and GDPDL3 expression (-2.11-fold, -2.52-fold, respectively), which would account for the implication of this new tomato miRNA and its targets in the response to P. syringae infection.

\section{Conclusions}

In this work, miRNAs associated with stress response in tomato were identified and analyzed by high-throughput sequencing. We have detected 37 miRNA families in tomato plant leaves undergoing six different stress conditions, and five miRNAs were found differentially expressed under drought, heat (5 miRNAs), CPB damage (6 miRNAs), P. syringae infection (17 miRNAs), B. cinerea infection (3 miRNAs), and Hx acid treatment (12 miRNAs). Collectively, our results highlight the interest in knowing the miRNAs involved in the regulation of different plant stress responses, as well as their putative shared or related targets to explain how plants integrate molecular and physiological adaptation to stress.

Supplementary Materials: The following are available online at http://www.mdpi.com/2073-4425/10/7/475/s1, Table S1: RT-qPCR primers for miRNAs and targets. Additional file 2: Table S2. Top miRNAs for each stress condition. Additional file 3: Table S3. Conserved miRNAs for each stress condition with sequence and reads. Additional file 4: Table S4. Novel miRNAs identified with characteristics. Table S5: Expression analysis data of high-throughput sequencing. Additional file 6: Table S6. Expression analysis data of high-throughput sequencing and RT-qPCR of ten selected stress-responsive miRNAs. Additional file 7: Table S7: Target prediction for conserved and novel differentially expressed miRNAs. Additional file 8: Table S8: GO terms for targets of conserved and novel differentially expressed miRNAs. Additional file 9: Table S9: Pairwise correlation values for all libraries.

Author Contributions: Conceptualization, I.G.-R.; Data curation, V.S. and A.C.-M.-R.; Formal analysis, C.R., M.D.R. and I.G.-R.; Funding acquisition, C.R., M.D.R. and I.G.-R.; Investigation, M.J.L.-G., C.R., M.D.R., G.C., O.R.-R. and O.C.-S.; Methodology, A.C.-M.-R.; Project administration, C.R., M.D.R. and I.G.-R.; Supervision, I.G.-R.; Writing—original draft, C.R., M.D.R. and I.G.-R.; Writing—review \& editing, C.R., M.D.R. and I.G.-R.

Funding: This work was supported by "MINECO" and "FEDER" (projects AGL2013-49023-C3-3-R, AGL2017-85987-C3-3-R). M.J. López-Galiano was awarded with a University of Valencia Ph. D. fellowship. O. Crespo-Salvador was recipient of research contract from grant AGL2013-49023-C03-01.

Acknowledgments: We thank the Genomics and Greenhouse Facilities from the SCSIE of the University of Valencia and the SCIC from the University Jaume I.

Conflicts of Interest: The authors declare no conflict of interest. The funders had no role in the design of the study; in the collection, analyses, or interpretation of data; in the writing of the manuscript, or in the decision to publish the results.

\section{References}

1. Djami-Tchatchou, A.T.; Sanan-Mishra, N.; Ntushelo, K.; Dubery, I.A. Functional roles of microRNAs in agronomically important plants-Potential as targets for crop improvement and protection. Front. Plant Sci. 2017, 8, 378. [CrossRef] [PubMed] 
2. Barciszewska-Pacak, M.; Milanowska, K.; Knop, K.; Bielewicz, D.; Nuc, P.; Plewka, P.; Pacak, A.M.; Vazquez, F.; Karlowski, W.; Jarmolowski, A.; et al. Arabidopsis microRNA expression regulation in a wide range of abiotic stress responses. Front. Plant Sci. 2015, 6, 410. [CrossRef] [PubMed]

3. Curaba, J.; Singh, M.B.; Bhalla, P.L. miRNAs in the crosstalk between phytohormone signalling pathways. J. Exp. Bot. 2014, 65, 1425-1438. [CrossRef] [PubMed]

4. Li, S.; Castillo-González, C.; Yu, B.; Zhang, X. The functions of plant small RNAs in development and in stress responses. Plant J. 2017, 90, 654-670. [CrossRef]

5. Kumar, R.; Khurana, A. Functional genomics of tomato: Opportunities and challenges in post-genome NGS era. J. Biosci. 2014, 39, 917-929. [CrossRef]

6. Borges, F.; Martienssen, R.A. The expanding world of small RNAs in plants. Nat. Rev. Mol. Cell Biol. 2015, 16, 1-15. [CrossRef] [PubMed]

7. Shivaprasad, P.V.; Chen, H.-M.; Patel, K.; Bond, D.M.; Santos, B.A.C.M.; Baulcombe, D.C.A. MicroRNA superfamily regulates nucleotide binding site-leucine-rich repeats and other mRNAs. Plant Cell. 2012, 24, 859-874. [CrossRef] [PubMed]

8. Bartel, D.P. MicroRNAs: Genomics, biogenesis, mechanism, and function. Cell 2004, 116, 281-297. [CrossRef]

9. Baulcombe, D. RNA silencing in plants. Nature 2004, 431, 356-363. [CrossRef]

10. Zhang, S.; Liu, Y.; Yu, B. New insights into pri-miRNA processing and accumulation in plants. Wiley Interdiscip. Rev. RNA 2015, 6, 533-545. [CrossRef]

11. Sun, G. MicroRNAs and their diverse functions in plants. Plant Mol. Biol. 2012, 80, 17-36. [CrossRef] [PubMed]

12. Feng, J.; Lin, R.; Chen, J. Alteration of tomato microRNAs expression during fruit development upon Cucumber mosaic virus and Tomato aspermy virus infection. Mol. Biol. Rep. 2013, 40, 3713-3722. [CrossRef]

13. Zhang, B.; Pan, X.; Cobb, G.P.; Anderson, T.A. Plant microRNA: A small regulatory molecule with big impact. Dev. Biol. 2006, 289, 3-16. [CrossRef]

14. Aukerman, M.J. Regulation of flowering time and floral organ identity by a MicroRNA and its Apetala2-like target genes. Plant Cell. 2003, 15, 2730-2741. [CrossRef] [PubMed]

15. Chen, X. A microRNA as a translational repressor of Apetala2 in Arabidopsis flower. Dev. Sci. 2004, 303, 2022-2025. [CrossRef]

16. Kamthan, A.; Chaudhuri, A.; Kamthan, M.; Datta, A. Small RNAs in plants: Recent development and application for crop improvement. Front. Plant Sci. 2015, 6, 208. [CrossRef]

17. Hoagland, D.R.; Arnon, D.I. The water-culture method for growing plants without soil. Circ. Calif. Agric. Exp. Stn. 1950, 347, 1-32.

18. King, E.O.; Ward, M.K.; Raney, D.E. Two simple media for the demonstration of pyocyanin and fluorescin. J. Lab. Clin. Med. 1954, 44, 301-307. [PubMed]

19. Katagiri, F.; Thilmony, R.; He, S.Y. The Arabidopsis thaliana-Pseudomonas syringae interaction. Arab. Book/Am. Soc. Plant Biol. 2002, 1, e0039. [CrossRef]

20. Schroeder, A.; Mueller, O.; Stocker, S.; Salowsky, R.; Leiber, M.; Gassmann, M.; Lightfoot, S.; Menzel, W.; Granzow, M.; Ragg, T. The RIN: An RNA integrity number for assigning integrity values to RNA measurements. BMC Mol. Biol. 2006, 7, 3. [CrossRef]

21. Balcells, I.; Cirera, S.; Busk, P.K. Specific and sensitive quantitative RT-PCR of miRNAs with DNA primers. BMC Biotechnol. 2011, 11, 70. [CrossRef] [PubMed]

22. Ruijter, J.M.; Ramakers, C.; Hoogaars, W.M.H.; Karlen, Y.; Bakker, O.; van den Hoff, M.J.B.; Moorman, A.F. Amplification efficiency: Linking baseline and bias in the analysis of quantitative PCR data. Nucleic Acids Res. 2009, 37, e45. [CrossRef]

23. Benjamini, Y.; Hochberg, Y. Controlling the false discovery rate: A practical and powerful approach to multiple testing. J. R. Stat. Soc. Ser. B 1995, 57, 289-300. [CrossRef]

24. Schwarz, D.; Thompson, A.J.; KlÃaring, H.-P. Guidelines to use tomato in experiments with a controlled environment. Front. Plant Sci. 2014, 5, 625. [CrossRef]

25. Turenne, N.; Andro, M.; Corbière, R.; Phan, T.T. Open data platform for knowledge access in plant health domain: VESPA mining. arXiv 2015, arXiv:1504.06077.

26. Sato, S.; Tabata, S.; Hirakawa, H.; Asamizu, E.; Shirasawa, K.; Isobe, S.; Kaneko, T.; Nakamura, Y.; Shibata, D.; Aoki, K.; et al. The tomato genome sequence provides insights into fleshy fruit evolution. Nature 2012, 485, 635-641. [CrossRef] 
27. Zhou, R.; Wang, Q.; Jiang, F.; Cao, X.; Sun, M.; Liu, M.; Zhen, W. Identification of miRNAs and their targets in wild tomato at moderately and acutely elevated temperatures by high-throughput sequencing and degradome analysis. Sci. Rep. 2016, 6, 33777. [CrossRef]

28. Candar-Cakir, B.; Arican, E.; Zhang, B. Small RNA and degradome deep sequencing reveals drought-and tissue-specific micrornas and their important roles in drought-sensitive and drought-tolerant tomato genotypes. Plant Biotechnol. J. 2016, 14, 1727-1746. [CrossRef]

29. Liu, M.; Yu, H.; Zhao, G.; Huang, Q.; Lu, Y.; Ouyang, B. Profiling of drought-responsive microRNA and mRNA in tomato using high-throughput sequencing. BMC Genom. 2017, 18, 481. [CrossRef]

30. Jin, W.; Wu, F. Characterization of miRNAs associated with Botrytis cinerea infection of tomato leaves. BMC Plant Biol. 2015, 15, 1. [CrossRef] [PubMed]

31. Xu, X.-W.; Li, T.; Li, Y.; Li, Z.-X. Identification and analysis of C. annuum microRNAs by high-throughput sequencing and their association with high temperature and high air humidity stress. Int. J. Bioautom. 2015, 19, 459-472.

32. Ma, C.; Burd, S.; Lers, A. miR408 is involved in abiotic stress responses in Arabidopsis. Plant J. 2015, 84, 169-187. [CrossRef]

33. Zhu, C.; Ding, Y.; Liu, H. MiR398 and plant stress responses. Physiol. Plant. 2011, 143, 1-9. [CrossRef] [PubMed]

34. Li, W.; Xu, Y.-P.; Cai, X.-Z. Transcriptional and posttranscriptional regulation of the tomato leaf mould disease resistance gene Cf-9. Biochem. Biophys. Res. Commun. 2016, 470, 163-167. [CrossRef]

35. Huang, J.; Yang, M.; Lu, L.; Zhang, X. Diverse functions of small RNAs in different plant-pathogen communications. Front. Microbiol. 2016, 7, 1552. [CrossRef] [PubMed]

36. Zhang, W.; Gao, S.; Zhou, X.; Chellappan, P.; Chen, Z.; Zhou, X.; Zhang, X.; Fromuth, N.; Coutino, G.; Coffey, M.; et al. Bacteria-responsive microRNAs regulate plant innate immunity by modulating plant hormone networks. Plant Mol. Biol. 2011, 75, 93-105. [CrossRef] [PubMed]

37. Li, S.-B.; Xie, Z.-Z.; Hu, C.-G.; Zhang, J.-Z. A review of auxin response factors (ARFs) in plants. Front. Plant Sci. 2016, 7, 47. [CrossRef] [PubMed]

38. Williams, L.; Carles, C.C.; Osmont, K.S.; Fletcher, J.C. A database analysis method identifies an endogenous trans-acting short-interfering RNA that targets the Arabidopsis ARF2, ARF3, and ARF4 genes. Proc. Natl. Acad. Sci. USA 2005, 102, 9703-9708. [CrossRef]

39. Cabrera, J.; Barcala, M.; García, A.; Rio-Machín, A.; Medina, C.; Jaubert-Possamai, S.; Favery, B.; Maizel, A.; Ruiz-Ferrer, V.; Fenoll, C.; et al. Differentially expressed small RNAs in Arabidopsis galls formed by Meloidogyne javanica: A functional role for miR390 and its TAS3-derived tasiRNAs. New Phytol. 2016, 209, 1625-1640. [CrossRef]

40. de Felippes, F.F.; Marchais, A.; Sarazin, A.; Oberlin, S.; Voinnet, O. A single miR390 targeting event is sufficient for triggering TAS3-tasiRNA biogenesis in Arabidopsis. Nucleic Acids Res. 2017, 45, 5539-5554. [CrossRef]

41. Fahlgren, N.; Howell, M.D.; Kasschau, K.D.; Chapman, E.J.; Sullivan, C.M.; Cumbie, J.S.; Givan, S.A.; Law, T.F.; Grant, S.R.; Dangl, J.L.; et al. High-Throughput sequencing of Arabidopsis microRNAs: Evidence for frequent birth and death of MIRNA genes. PLoS ONE 2007, 2, e219. [CrossRef]

42. Ouyang, S.; Park, G.; Atamian, H.S.; Han, C.S.; Stajich, J.E.; Kaloshian, I.; Borkovich, K.A. MicroRNAs suppress NB domain genes in tomato that confer resistance to Fusarium oxysporum. PLoS Pathog. 2014, 10, e1004464. [CrossRef] [PubMed]

43. Montgomery, T.A.; Howell, M.D.; Cuperus, J.T.; Li, D.; Hansen, J.E.; Alexander, A.L.; Chapman, E.J.; Fahlgren, N.; Allen, E.; Carrington, J.C. Specificity of Argonaute7-miR390 interaction and dual functionality in TAS3 trans-acting siRNA formation. Cell 2008, 133, 128-141. [CrossRef]

44. Rubio-Somoza, I.; Weigel, D. MicroRNA networks and developmental plasticity in plants. Trends Plant Sci. 2011, 16, 258-264. [CrossRef] [PubMed]

45. Wang, Y.; Li, L.; Tang, S.; Liu, J.; Zhang, H.; Zhi, H.; Guanqing, J.; Diao, X. Combined small RNA and degradome sequencing to identify miRNAs and their targets in response to drought in foxtail millet. BMC Genet. 2016, 17, 57. [CrossRef]

46. Tian, C.; Zuo, Z.; Qiu, J.-L. Identification and characterization of ABA-responsive MicroRNAs in rice. J. Genet. Genom. 2015, 42, 393-402. [CrossRef] [PubMed] 
47. Melotto, M.; Underwood, W.; Koczan, J.; Nomura, K.; He, S.Y. Plant stomata function in innate immunity against bacterial invasion. Cell 2006, 126, 969-980. [CrossRef] [PubMed]

48. Ni, Z.; Hu, Z.; Jiang, Q.; Zhang, H. GmNFYA3, a target gene of miR169, is a positive regulator of plant tolerance to drought stress. Plant Mol. Biol. 2013, 82, 113-129. [CrossRef]

49. Li, W.-X.; Oono, Y.; Zhu, J.; He, X.-J.; Wu, J.-M.; Iida, K.; Lu, X.Y.; Cui, X.; Jin, H.; Zhu, J.K. The Arabidopsis NFYA5 transcription factor is regulated transcriptionally and posttranscriptionally to promote drought resistance. Plant Cell 2008, 20, 2238-2251. [CrossRef] [PubMed]

50. Li, F.; Pignatta, D.; Bendix, C.; Brunkard, J.O.; Cohn, M.M.; Tung, J.; Sun, H.; Kumar, P.; Baker, B. MicroRNA regulation of plant innate immune receptors. Proc. Natl. Acad. Sci. USA 2012, 109, 1790-1795. [CrossRef] [PubMed]

51. Cuperus, J.T.; Carbonell, A.; Fahlgren, N.; Garcia-Ruiz, H.; Burke, R.T.; Takeda, A.; Sullivan, C.M.; Gilbert, S.D.; Montgomery, T.A.; Carrington, J.C. Unique functionality of 22-nt miRNAs in triggering RDR6-dependent siRNA biogenesis from target transcripts in Arabidopsis. Nat. Struct. Mol. Biol. 2010, 17, 997-1003. [CrossRef]

52. Chi, M.; Liu, C.; Su, Y.; Tong, Y.; Liu, H. Bioinformatic prediction of upstream microRNAs of PPO and novel microRNAs in potato. Can. J. Plant Sci. 2015, 95, 871-877. [CrossRef]

53. Gazzani, S.; Li, M.; Maistri, S.; Scarponi, E.; Graziola, M.; Barbaro, E.; Wunder, J.; Furini, A.; Saedler, H.; Varotto, C. Evolution of MIR168 paralogs in brassicaceae. BMC Evol. Biol. 2009, 9, 62. [CrossRef]

54. Li, C.; Zhang, B. MicroRNAs in control of plant development. J. Cell. Physiol. 2016, 231, 303-313. [CrossRef] [PubMed]

55. Bozorov, T.A.; Baldwin, I.T.; Kim, S.-G. Identification and profiling of miRNAs during herbivory reveals jasmonate-dependent and -independent patterns of accumulation in Nicotiana attenuata. BMC Plant Biol. 2012, 12, 209. [CrossRef]

56. Gao, Z.-H.; Yang, Y.; Zhang, Z.; Zhao, W.-T.; Meng, H.; Jin, Y.; Huang, J.Q.; Xu, Y.H.; Zhao, L.Z.; Liu, J.; et al. Profiling of microRNAs under wound treatment in Aquilaria sinensis to identify possible microRNAs involved in agarwood formation. Int. J. Biol. Sci. 2014, 10, 500-510. [CrossRef] [PubMed]

57. Sarkar, D.; Maji, R.K.; Dey, S.; Sarkar, A.; Ghosh, Z.; Kundu, P. Integrated miRNA and mRNA expression profiling reveals the response regulators of a susceptible tomato cultivar to early blight disease. DNA Res. 2017, 24, 235-250. [CrossRef] [PubMed]

58. Aranega-Bou, P.; de la O Leyva, M.; Finiti, I.; García-Agustín, P.; González-Bosch, C. Priming of plant resistance by natural compounds. Hexanoic acid as a model. Front. Plant Sci. 2014, 5, 488. [CrossRef] [PubMed]

59. Conrath, U.; Beckers, G.J.M.; Langenbach, C.J.G.; Jaskiewicz, M.R. Priming for enhanced defense. Ann. Rev. Phytopathol. 2015, 53, 97-119. [CrossRef] [PubMed]

60. Crisp, P.A.; Ganguly, D.; Eichten, S.R.; Borevitz, J.O.; Pogson, B.J. Reconsidering plant memory: Intersections between stress recovery, RNA turnover, and epigenetics. Sci. Adv. 2016, 2, e1501340. [CrossRef]

61. Espinas, N.A.; Saze, H.; Saijo, Y. Epigenetic control of defense signaling and priming in plants. Front. Plant Sci. 2016, 7, 1201. [CrossRef] [PubMed]

62. Lämke, J.; Bäurle, I. Epigenetic and chromatin-based mechanisms in environmental stress adaptation and stress memory in plants. Genome Biol. 2017, 18, 124. [CrossRef] [PubMed]

63. Stief, A.; Altmann, S.; Hoffmann, K.; Pant, B.D.; Scheible, W.-R.; Bäurle, I. Arabidopsis miR156 regulates tolerance to recurring environmental stress through SPL transcription factors. Plant Cell. 2014, 26, 1792-1807. [CrossRef] [PubMed]

64. Soto-Suárez, M.; Baldrich, P.; Weigel, D.; Rubio-Somoza, I.; San Segundo, B. The Arabidopsis miR396 mediates pathogen-associated molecular pattern-triggered immune responses against fungal pathogens. Sci. Rep. 2017, 7, 44898. [CrossRef]

65. Vicedo, B.; Flors, V.; de la O Leyva, M.; Finiti, I.; Kravchuk, Z.; Real, M.D.; García-Agustín, P.; González-Bosch, C. Hexanoic acid-induced resistance against Botrytis cinerea in tomato plants. Mol. Plant. Microbe Interact. 2009, 22, 1455-1465. [CrossRef]

66. Small, I.D.; Peeters, N. The PPR motif-A TPR-related motif prevalent in plant organellar proteins. Trends Biochem. Sci. 2000, 25, 46-47. [CrossRef]

67. Lurin, C.; Andrés, C.; Aubourg, S.; Bellaoui, M.; Bitton, F.; Bruyère, C.; Caboche, M.; Debast, C.; Gualberto, J.; Hoffmann, B.; et al. Genome-wide analysis of Arabidopsis pentatricopeptide repeat proteins reveals their essential role in organelle biogenesis. Plant Cell. 2004, 16, 2089-2103. [CrossRef] 
68. Schaper, E.; Anisimova, M. The evolution and function of protein tandem repeats in plants. New Phytol. 2015, 206, 397-410. [CrossRef]

69. Sharma, M.; Pandey, G.K. Expansion and function of repeat domain proteins during stress and development in plants. Front. Plant Sci. 2016, 6, 1218. [CrossRef] [PubMed]

70. Park, S.; Gupta, R.; Krishna, R.; Kim, S.T.; Lee, D.Y.; Hwang, D.-J.; Bae, S.-C.; Ahn, I.-P. Proteome analysis of disease resistance against Ralstonia solanacearum in potato cultivar CT206-10. Plant Pathol. J. 2016, 32, 25-32. [CrossRef]

71. Laluk, K.; AbuQamar, S.; Mengiste, T. The Arabidopsis mitochondria-localized pentatricopeptide repeat protein PGN functions in defense against necrotrophic fungi and abiotic stress tolerance. Plant Physiol. 2011, 156, 2053-2068. [CrossRef]

72. Day, B.; Henty, J.L.; Porter, K.J.; Staiger, C.J. The pathogen-actin connection: A platform for defense signaling in plants. Ann. Rev. Phytopathol. 2011, 49, 483-506. [CrossRef]

73. Rodríguez-Milla, M.A.; Salinas, J. Prefoldins 3 and 5 play an essential role in Arabidopsis tolerance to salt stress. Mol. Plant. 2009, 2, 526-534. [CrossRef]

74. Shimono, M.; Lu, Y.-J.; Porter, K.; Kvitko, B.H.; Henty-Ridilla, J.; Creason, A.; He, S.Y.; Chang, J.H.; Staiger, C.J.; Day, B. The Pseudomonas syringae type III effector HopG1 induces actin remodeling to promote symptom development and susceptibility during infection. Plant Physiol. 2016, 171, 2239-2255. [CrossRef] [PubMed]

75. Huang, W.; Xian, Z.; Kang, X.; Tang, N.; Li, Z. Genome-wide identification, phylogeny and expression analysis of GRAS gene family in tomato. BMC Plant Biol. 2015, 15, 209. [CrossRef]

76. Wang, L.; Mai, Y.-X.; Zhang, Y.-C.; Luo, Q.; Yang, H.-Q. MicroRNA171c-targeted SCL6-II, SCL6-III, and SCL6-IV genes regulate shoot branching in Arabidopsis. Mol. Plant. 2010, 3, 794-806. [CrossRef]

77. Llave, C.; Xie, Z.; Kasschau, K.D.; Carrington, J.C. Cleavage of Scarecrow-like mRNA targets directed by a class of Arabidopsis miRNA. Science 2002, 297, 2053-2056. [CrossRef] [PubMed]

78. Huang, W.; Peng, S.; Xian, Z.; Lin, D.; Hu, G.; Yang, L.; Ren, M.; Li, Z. Overexpression of a tomato miR171 target gene SlGRAS24 impacts multiple agronomical traits via regulating gibberellin and auxin homeostasis. Plant Biotechnol. J. 2017, 15, 472-488. [CrossRef] [PubMed]

79. Mayrose, M.; Ekengren, S.K.; Melech-Bonfil, S.; Martin, G.B.; Sessa, G. A novel link between tomato GRAS genes, plant disease resistance and mechanical stress response. Mol. Plant Pathol. 2006, 7, 593-604. [CrossRef]

80. Schmidt, D.D.; Voelckel, C.; Hartl, M.; Schmidt, S.; Baldwin, I.T. Specificity in ecological interactions. attack from the same lepidopteran herbivore results in species-specific transcriptional responses in two solanaceous host plants. Plant Physiol. 2005, 138, 1763-1773. [CrossRef] [PubMed]

81. Wilkens, S. Structure and mechanism of ABC transporters. F1000Prime Rep. 2015, 7, 14. [CrossRef] [PubMed]

82. Bisgrove, S.R.; Simonich, M.T.; Smith, N.M.; Sattler, A.; Innes, R.W. A disease resistance gene in Arabidopsis with specificity for two different pathogen avirulence genes. Plant Cell. 1994, 6, 927-933. [CrossRef] [PubMed]

83. Wu, J.; Hettenhausen, C.; Meldau, S.; Baldwin, I.T. Herbivory rapidly activates MAPK signaling in attacked and unattacked leaf regions but not between leaves of Nicotiana attenuata. Plant Cell 2007, 19, 1096-1122. [CrossRef] [PubMed]

84. Kretzschmar, T.; Burla, B.; Lee, Y.; Martinoia, E.; Nagy, R. Functions of ABC transporters in plants. Essays Biochem. 2011, 50, 145-160. [CrossRef] [PubMed]

85. Bienert, M.D.; Siegmund, S.E.G.; Drozak, A.; Trombik, T.; Bultreys, A.; Baldwin, I.T.; Boutry, M. A pleiotropic drug resistance transporter in Nicotiana tabacum is involved in defense against the herbivore Manduca sexta. Plant J. 2012, 72, 745-757. [CrossRef] [PubMed]

86. Draeger, C.; Ndinyanka Fabrice, T.; Gineau, E.; Mouille, G.; Kuhn, B.M.; Moller, I.; Abdou, M.-T.; Frey, B.; Pauly, M.; Bacic, A.; et al. Arabidopsis leucine-rich repeat extensin (LRX) proteins modify cell wall composition and influence plant growth. BMC Plant Biol. 2015, 15, 155. [CrossRef] [PubMed]

87. Hayashi, S.; Ishii, T.; Matsunaga, T.; Tominaga, R.; Kuromori, T.; Wada, T.; Shinozaki, K.; Hirayama, T. The glycerophosphoryl diester phosphodiesterase-like proteins SHV3 and its homologs play important roles in cell wall organization. Plant Cell Physiol. 2008, 49, 1522-1535. [CrossRef] [PubMed]

(C) 2019 by the authors. Licensee MDPI, Basel, Switzerland. This article is an open access article distributed under the terms and conditions of the Creative Commons Attribution (CC BY) license (http://creativecommons.org/licenses/by/4.0/). 